\title{
Muscarinic Modulation of a Pattern-Generating Network: Control of Neuronal Properties
}

\author{
Thierry Bal, a Frédéric Nagy, and Maurice Moulins \\ Université de Bordeaux I-C.N.R.S URA 1126, Laboratoire de Neurobiologie et Physiologie Comparées, 33120 Arcachon, \\ France
}

The aim of this article is to investigate the cellular mechanisms underlying cholinergic modulation of the pyloric network in the stomatogastric ganglion (STG) of the Cape lobster Jasus lalandii. Bath application of the muscarinic agonists muscarine, oxotremorine, and pilocarpine on the STG activates a rhythmic pattern from a quiescent pyloric network. The mechanisms of this modulation were investigated on individual pyloric neurons isolated both from synaptic interactions within the network (by photoinactivation of most of the presynaptic neurons and pharmacological blockade of the remaining synapses) and from central inputs (by a sucrose block of the input nerve). All three muscarinic agonists activated bursting and plateau properties of all the neurons comprising the pyloric network. The activation was dose dependent, and was blocked by the muscarinic antagonists atropine, pirenzepine, and scopolamine. The oscillatory behavior triggered by the muscarinic stimulation was specific to each type of pyloric neuron. The isolated neuron $A B$ had the shortest oscillation period and depolarizing phase. The constrictor neurons (LP, PY, IC) were the slowest oscillators, and only oscillated upon hyperpolarizing current injection. Under muscarinic modulation, the individual bursting activities of the isolated pyloric neurons were of the same type as their activities when isolated from the network but modulated by central inputs (Bal et al., 1988). The VD neuron is an exception since it was a rapid oscillator in the latter situation and became a slow oscillator when modulated by a single muscarinic agonist. To determine the relative importance of the muscarinic-dependent bursting properties of the individual pyloric neurons in the operation of the intact network, a progressive reconstruction of the synaptic circuitry was attempted. We found that under certain conditions of muscarinic modulation a new composite pacemaker could be created, composed of the electrically coupled VD, AB, and PD neurons. This can result in the generation of new pyloric patterns that were very sensitive to the membrane potential of individual network neurons. The data also con-

\footnotetext{
Feb. 2, 1993; revised Oct. 22, 1993; accepted Nov. 1, 1993.

This work was supported by CNRS Grant 1126 and a grant from the Human Frontier Science Program. We thank Dr. Ron M. Harris-Warrick for careful reading of the manuscript and for his many helpful suggestions, and Dr. Patrice Cardi for his help during preparation of the manuscript.

Correspondence should be addressed to Frédéric Nagy, I aboratoire de Neurobiologie et Physiologie Comparées, Place du Docteur Bertrand Peyneau, 33120 Arcachon, France.

"Present address: Section of Neurobiology, Sterling Hall of Medicine C303, Yale University Medical School, 333 Cedar Street, New Haven, Connecticut 06510.

Copyright (c) 1994 Society for Neuroscience $0270-6474 / 94 / 143019-17 \$ 05.00 / 0$
}

firmed that, in a rhythmic "pattern-generating network," the pacemaker role may not be definitely attributed to a given neuron but instead could be assigned to other neurons by modulation of their respective oscillatory capabilities.

IKey words: motor pattern generation, stomatogastric, Crustacea, in situ isolated neurons, muscarinic modulation, oscillations, pacemaker]

The generation of simplc motor bchaviors in both vertebrates and invertebrates is the product of limited ensembles of neurons within the CNS. These central pattern generators (CPG) determine the rhythm and the sequential organization of the motoneuronal discharges that underlie rhythmic motor patterns (Delcomyn, 1980; Selverston and Moulins, 1985; McCrohan, 1988). We have learned from the study of both vertebrate and invertebrate nervous systems that a single network has a built-in capability to produce a number of different patterns that correspond to different motor behaviors (Berkinblit et al., 1978; Ayers et al., 1983; Bekoff et al., 1987; Pearson, 1987; Gelfand et al., 1988; Harris-Warrick and Johnson, 1989; Harris-Warrick and Marder, 1991), but that a detailed knowledge of the network connectivity alone is not sufficient to account for its versatile operation. Rather, the cellular and synaptic properties of the component neurons and their modulation by extrinsic inputs are at least as important (Selverston et al., 1983; Moulins and Nagy, 1985; Harris-Warrick, 1988; Calabrese et al., 1989; Getting, 1989; Harris-Warrick et al., 1992b).

A great deal of information on the mechanisms of network operation and flexibility has come from studies of the crustacean stomatogastric nervous system (Selverston and Moulins, 1987; Harris-Warrick et al., 1992a). Two of the major CPG circuits of this system, the pyloric and the gastric networks located in the stomatogastric ganglion (STG; Fig. 1 $A$ ), are well known in terms of their cellular components and synaptic interactions (reviewed in Selverston and Moulins, 1987). In the Cape lobster Jasus lalandii the pyloric circuit is comprised of one interneuron $(\mathrm{AB})$ and 13 motor neurons (Fig. $1 B$ ). In a previous article (Bal et al., 1988), we have demonstrated that all the neurons comprising the pyloric CPG are cellular oscillators. When isolated in situ from their partners in the network, they can be classified in different categories related to their specific oscillatory behavior. We have shown, in addition, that each of these neuronal oscillators is conditional and requires modulatory inputs in order to express its oscillatory capabilities. The conclusion was that the basic pyloric motor pattern results from a complex interaction between different conditional oscillators, one of which (the interneuron $\mathrm{AB}$ ) is normally the pacemaker. Understanding 

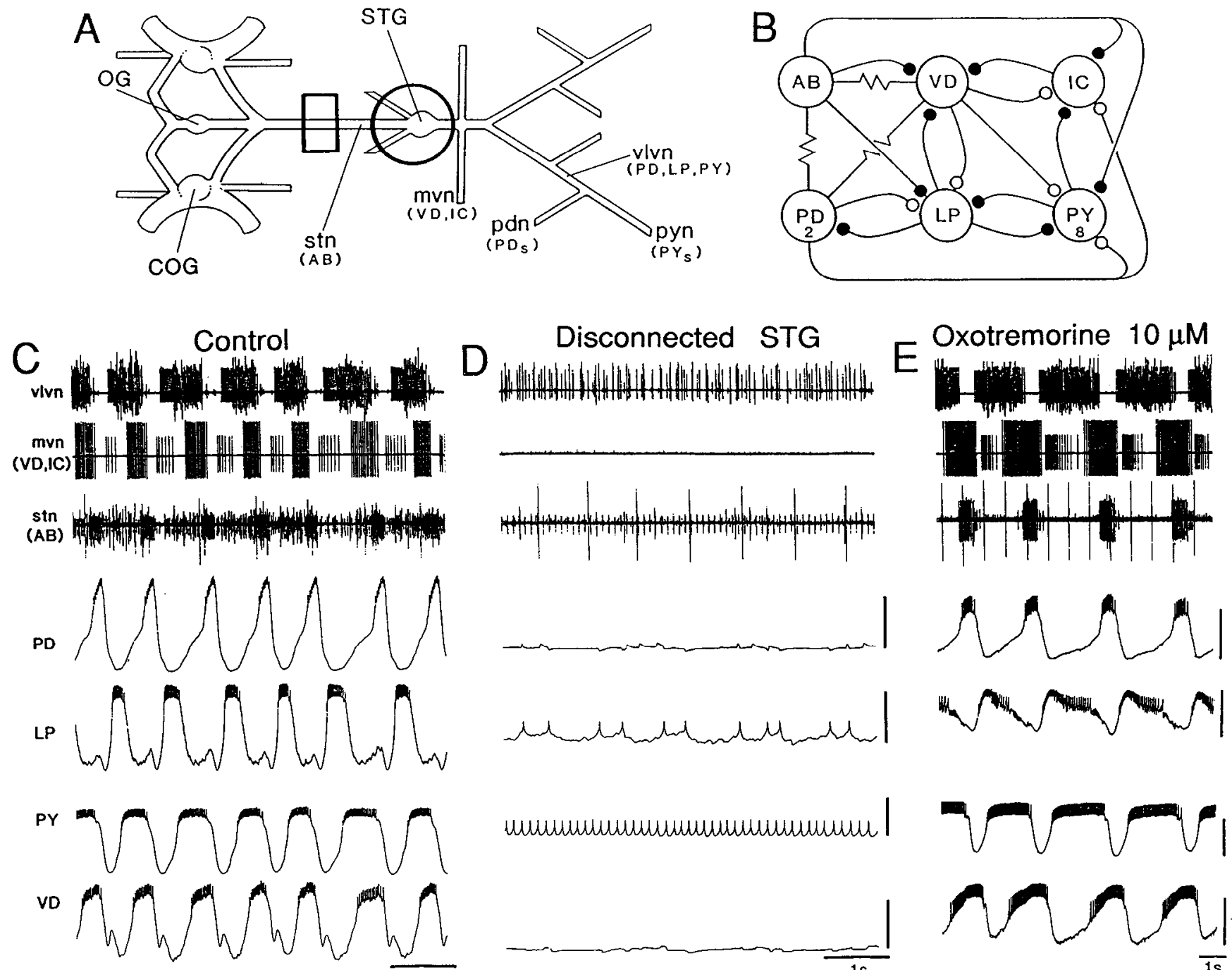

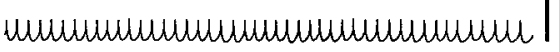

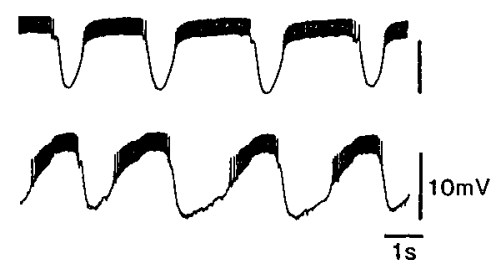

Figure 1. The muscarinic agonist oxotremorine induces a rhythmic activity of the pyloric network disconnected from anterior ganglia. A, Diagram of the in vitro preparation of the stomatogastric nervous system. The rectangle indicates the location of a sucrose block on the $s t n ;$ the $c i r c l e$ indicates a perfusion chamber around the STG. B, Pyloric neurons and their synaptic interactions within the pyloric network. Solid circles, glutamatergic inhibitory connections; open circles, cholinergic inhibitory connections; resistance symbol, electrotonic synapses. $C$, Spontaneous pyloric rhythm with intact input from higher ganglia; simultaneous intracellular recordings from two dilator $(P D$ and $V D)$ and two constrictor $(L P$ and $P Y)$ motor neurons, and extracellular recordings from the input nerve $(s t n)$ and two motor nerves $(v l v n, m v n)$. The $v l v n$ extracellular activity is recorded after the bifurcation of the $p d n$ allowing to record only the $L P$ and $P Y$ discharges. $D$, After blockade of impulse traffic in the stn the pyloric rhythm stops. $E$, Perfusion of the STG with oxotremorine $(10 \mu \mathrm{M})$ induces a rhythmic pyloric pattern. $C-E$ are from the same preparation. $A B$, anterior burster neuron; $C O G$, commissural ganglion; $I C$, inferior cardiac neuron; $L P$, lateral pyloric neuron; $m v n$, medial ventricular nerve; $O G$, esophageal ganglion; $P D$, pyloric dilator neuron; $p d n$, PD nerve; $P Y$, pyloric ncuron; pyn, PY nerve; $S T G$, stomatogastric ganglion; stn stomatogastric nerve; $V D$, ventricular dilator neuron; $v / v n$, ventral lateral ventricular nerve.

the basis for the differences in oscillatory behavior of the individual pyloric neurons is therefore of critical importance to understand the flexible operation of the network.

These differences are most probably due to both differences between the intrinsic characteristics of neurons (i.e., the set of membrane currents and/or differential sensitivity to the same neuromodulator), and differential distribution of a number of neuromodulatory inputs that promotes specific oscillatory behaviors in different target neurons. In order to determine in which proportion these two factors influence the operation of the pyloric network, one may examine the control by a single neuromodulator of the individual oscillatory behaviors of every pyloric neuron, under conditions where the latter are isolated both from the network synaptic interactions and from central modulatory inputs. Dissection of the network can be performed by using a photoinactivation technique (Miller and Selverston, 1979). Miller and Selverston (1982) clearly demonstrated the advantages of deleting network elements to describe the ability of remaining subsets to generate specific components of the pyloric rhythm. Subsequent studies confirmed the interest of this approach by considering the role of modulation by various neurotransmitters on a number of individual target neurons and deducing their role in controlling specific features of the network output (Marder and Eisen, 1984; Flamm and Harris-Warrick, 1986a,b; Hooper and Marder, 1987).

Following the same conceptual framework, we investigated in the present study the effects of muscarinic cholinergic agonists (muscarine, oxotremorine, and pilocarpine) on pyloric neurons isolated in situ from network interactions. Muscarinic agonists are known to trigger rhythmic patterns from the pyloric (Raper, 
1979; Marder and Eisen, 1984; Nagy et al., 1985) and the gastric mill networks (Elson and Selverston, 1992). Marder and Eisen (1984) have demonstrated that muscarinic stimulation induces rhythmic bursting in the isolated $\mathrm{AB}$ and PD neurons, which are the pacemakers of the pyloric network. Our data extended the analysis to all pyloric neurons, and showed that they all respond in a specific way to muscarinic modulation. Then, by considering the effects of the muscarinic agonists on a subsct of coupled neurons, and finally on the intact network, we gained insight into the complex manner in which muscarinic modulation of the rhythmogenic properties of individual neurons is integrated within the intact network.

\section{Materials and Methods}

Preparation and recording techniques. Male and female Cape lobsters (Jasus lalandii) were purchased from commercial suppliers (Cap Langouste, Nice, France). Animals were maintained in large tanks of circulating and aerated seawater. The stomatogastric nervous system (Fig. $1 A$ ) dissected from the stomach was pinned in a Sylgard-lined petri dish and maintained at $17^{\circ} \mathrm{C}$ by means of a Peltier cooling cell, in oxygenated saline of the following composition (mM): $\mathrm{NaCl}, 479.12 ; \mathrm{KCl}, 12.74$; $\mathrm{MgSO}_{4}, 10 ; \mathrm{Na}_{2} \mathrm{SO}_{4}, 3.91 ; \mathrm{CaCl}_{2} \cdot 2 \mathrm{H}_{2} \mathrm{O}, 13.67 ;$ HEPES, 5; pH 7.45. The stomatogastric ganglion (STG) was desheathed to allow access to pyloric neuron somata. Recording techniques and procedure for identification of the pyloric neurons were described previously (Bal et al., 1988). Synaptic interconnections in the pyloric network (Fig. 1B) described in Panulirus (Selverston et al., 1976; Mulloney, 1987) are identical in Jasus (Nagy and Dickinson, 1983).

In situ isolation of pyloric neurons. Two experimental conditions were used to suppress synaptic inputs to pyloric neurons. In the first situation, used in Figure $9 A$, a selected pyloric neuron, which we will refer to as "isolated from network," was deprived of synaptic inputs from other neurons in the network, but was still influenced by inputs from rostral centers (COGs, OG; see Fig. $1 A$ ). For the remaining experiments on isolated neurons, the cell under study, which we will refer to as "isolated + STG disconnected," was deprived of any kind of known synaptic input by additional reversible blockade of impulse traffic in the stomatogastric nerve (stn), the single input nerve to the STG (Fig. 1A).

Synaptic isolation of a neuron within the pyloric network was achieved by photoinactivation (Miller and Selverston, 1979), of neurons to which it is electrically coupled (with the exception of the eight electrically coupled PY neurons, which were not isolated from each other), and also of its cholinergic presynaptic neurons (two PDs and VD; Marder, 1976; see Fig. $1 B$ ). Isolation of pyloric neurons was completed by blockade of synaptic inputs from glutamatergic neurons in the network (neurons $\mathrm{AB}, \mathrm{LP}, \mathrm{PY}, \mathrm{LC})$ with $10 \mu \mathrm{M}$ picrotoxin in the perfusion saline (Bidaut, 1980). The detailed procedure for isolation of each pyloric neuron is given in Bal et al. (1988).

The stomatogastric ganglion was reversibly disconnected from anterior ganglia by means of a sucrose block on the stomatogastric nerve (stn, Fig. 1 $A$ ). A desheathed portion of the stn was surrounded by a Vaseline chamber and perfused with an isotonic (750 mM) sucrose solution ( $\mathrm{pH}$ adjusted to 7.45 with $\mathrm{NH}_{4} \mathrm{OH}$ ). Impulse conduction was considered to be completely blocked when electrical stimulation of the stn rostral to the sucrose gap had no effect on the activity of the pyloric neurons. Another Vaseline chamber was built around the STG for bath application of drugs diluted in the saline. The following compounds were purchased from Sigma: atropine sulfate, Lucifer yellow CH, DLmuscarine chloride, oxotremorine sesquifumarate, picrotoxin, pilocarpine hydrochloride, scopolamine hydrochloride, and $d$-tubocurarine chloride. Pirenzepine dihydrochloride was a gift from Bochringer-Ingelheim.

Error bars in figures and \pm numbers in text are standard deviations. Significance of differences between values were evaluated with a Student's $t$ test.

\section{Results}

When the stomatogastric nervous system is studied in vitro (Fig. $1 A$ ), the STG displays a fictive pyloric motor pattern similar to that recorded in the intact animal (Rezer and Moulins, 1983). This spontaneous pattern of the pyloric network, extensively studied over the past two decades (Miller, 1987; Mulloney, 1987; Harris-Warrick et al., 1992b), is illustrated in Figure 1C. Briefly, all the intracellularly recorded neurons show rhythmic oscillations of their membrane potential and rhythmic bursting organized in the following order (AB+2PDs, LP+IC, 8PYs + VD). The interneuron $\mathrm{AB}$ and the two motor neurons PDs are strongly electrically coupled, fire synchronously, and are classically considered as the pacemaker unit. The organization of the pyloric sequence relies mainly on chemical synaptic connections between the pyloric neurons, which are all inhibitory (Fig. $1 B$ ). In particular, the pacemaker neurons $(\mathrm{AB}+2 \mathrm{PDs})$ inhibit all the follower neurons (LP, IC, PYs, and VD), which then rebound to fire at different phases. Descending inputs to the STG from anterior ganglia (COG and OG) activate and enhance pyloric activity (Russell, 1979). When these inputs are eliminated (by preventing axonal conduction in the input nerve stn to the STG with a sucrose block), rhythmic pyloric activity vanishes (Fig. $1 D$; Miller and Selverston, 1982; Moulins and Cournil, 1982; Nagy and Miller, 1987). Under these experimental conditions, none of the pyloric neurons are able to oscillate, either at rest or when their membrane potential is modified by current injection (Bal et al., 1988). These results imply that modulatory influences originating in the anterior ganglia are of primary importance for the normal operation of the pyloric network. A number of modulatory neurons have been identified that could contribute to pyloric oscillations (reviewed in Katz and HarrisWarrick, 1990).

Since our purpose was to study the isolated actions of muscarinic agonists, our experiments were done under conditions where all the modulatory inputs naturally impinging upon the network were blocked. Inputs from premotor ganglia were eliminated with a sucrose block on the stn, and peripheral serotonergic inputs from the gastropyloric receptor cells (Katz et al., 1989) were eliminated by cutting out the peripheral nerves containing their somata. In the Cape lobster Jasus lalandii, under such conditions the pyloric rhythm disappeared after $10 \mathrm{~min}$ of stn block in most of the experiments (41 of 49). The few remaining preparations were not included in the present study. In the STG, ACh-releasing pathways provoke at least three different postsynaptic effects: inhibition of the constrictor neurons (LP, PY, and IC) by the cholinergic neurons PD and VD (Marder, 1976), nicotinic excitation of the PD neurons by the extrinsic cholinergic neuron CD1 (Bal, 1991), and the muscarinic slow modulatory effect that is studied in this article. To characterize the effects of ACh on muscarinic receptors only, muscarinic agonists (muscarine, oxotremorine, and pilocarpine) were applied in the bath solution at known concentrations.

\section{A pyloric rhythm is elicited under muscarinic stimulation}

In the experiment of Figure 1, after inputs to the STG were blocked, a sustained pyloric activity was reinduced by the muscarinic agonist oxotremorine (10 $\mu \mathrm{M}$; Fig. $1 E)$. The records of Figure 1 show that all types of pyloric neurons switched their activity from tonic firing or silence when the network was disconnected (Fig. $1 D$ ) to a bursting mode evoked by oxotremorine (Fig. $1 E$ ). The motor neuron discharges were organized in a triphasic sequence (PD, LP, PY) that resembles the pyloric sequence in the intact system (compare Fig. 1C,E). The pattern induced by muscarinic stimulation, however, depended on the dose of the modulator. This is shown in Figure 2, where the effects of increasing concentrations of oxotremorine were recorded using only extracellular electrodes. The experimental 
A

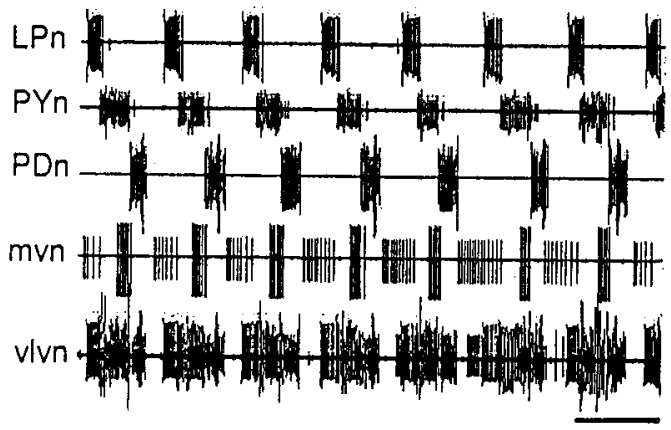

C

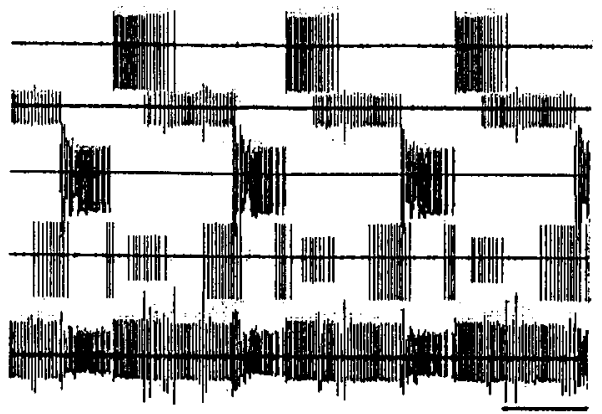

$E$ connected STG under increasing concentrations of oxotremorine $(B-D)$. All panels are from the same representative experiment. In $C$ and $D$, the patterns were stable over more than $30 \mathrm{~min}$, whereas in $B$ it varied considerably in period, burst durations, and phasing (not shown). $E$ and $F$, Phase-normalized plots of the data shown in $A$ and $D$, respectively. The normalized cycles start $(O)$ at the beginning of a PD burst, and end $(l)$ at the beginning of the next PD burst. Two consecutive cycles of the pattern are plotted. The onset and termination of each burst are means from 20 measurements. Error bars are \pm SDs. For conclusions, see text.

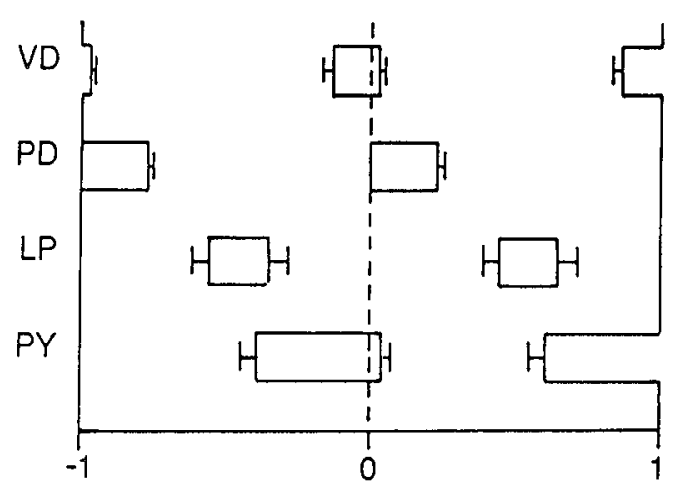

control

B oxotremorine $0.25 \mu \mathrm{M}$

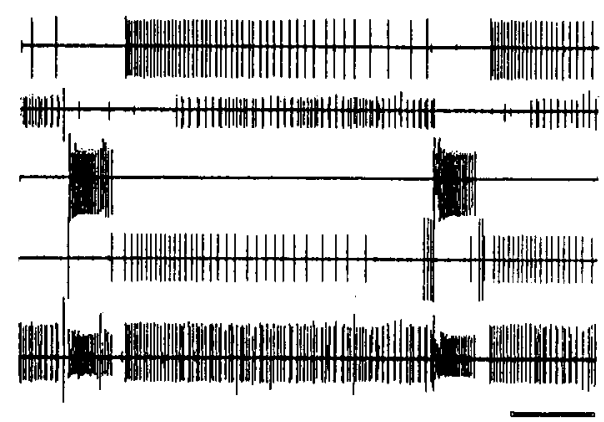

D

oxotremorine $1 \mu \mathrm{M}$

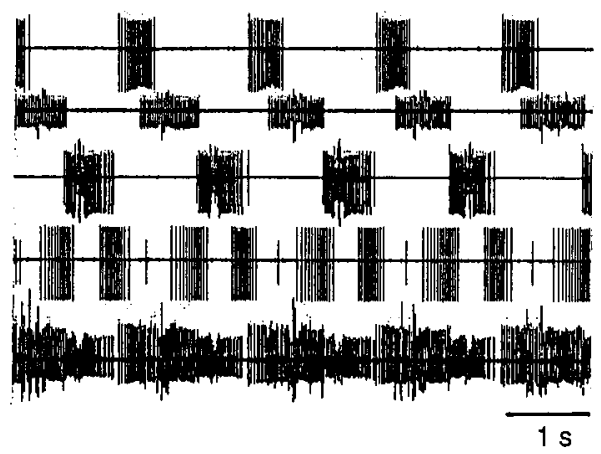

$\mathrm{F}$

oxotremorine $1 \mu \mathrm{M}$

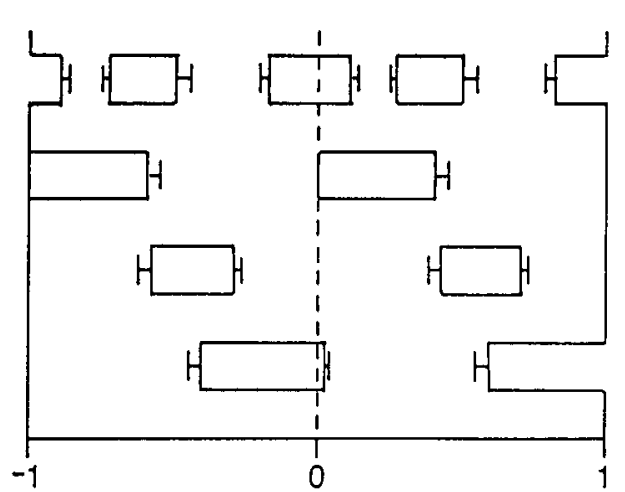

conditions were those of Figure $1 E$ (disconnected STG), and successive applications of the modulator were separated by 30 min wash. The threshold concentration was $0.1 \mu \mathrm{M}$, and the effects saturated at $1 \mu \mathrm{M}$, with no significant change up to 10 $\mu \mathrm{M}$. Clearly, burst period, burst duration, firing frequency, and phase relationships varied with the concentration of oxotremorine. Stability of the pattern also varied with concentration of the modulator. In this sensitive preparation, the organization of the sequence was stable over more than 30 min with $1 \mu \mathrm{M}$ oxotremorine (Fig. 2D) and higher concentrations, but considerably varied with time at lower doses of the modulator $(0.25$ $\mu \mathbf{M}$, Fig. $2 B ; 0.5 \mu \mathrm{M}$, not shown).

Although, saturating concentration varied from preparation to preparation (e.g., $1 \mu \mathrm{M}$ in Fig. 2, $10 \mu \mathrm{M}$ in Fig. 1), it produced a rather characteristic pattern that differed to some extent from the pyloric pattern in the intact system. The period of the rhythm was longer, and the intensity of firing was increased for every neuron. Also, the duty cycle (fraction of the cycle where the neuron is active) and phase relationships were different (Fig. $2 E, F)$. For example, the discharge of the VD neuron that was terminated at the onset of the discharges of the AB-PD neurons in the control (Fig. 2E) largely overlapped those discharges under oxotremorine. The AB-derived inhibition can interrupt briefly the VD discharges resulting in double bursts of the VD neuron (Fig. $2 C, D, F$ ), or can be almost inefficient, the AB, PD, and VD neurons firing in phase (Fig. $1 E$ ). The discharges of the constrictor LP and PY neurons also showed larger overlap under oxotremorine than in control (compare Fig. $2 E, F$ ). Finally, the silence gap between the PD and LP discharges was often decreased or suppressed under muscarinic stimulation (compare vlvn in Fig. 2A,D).

These results demonstrate that in a disconnected STG that 


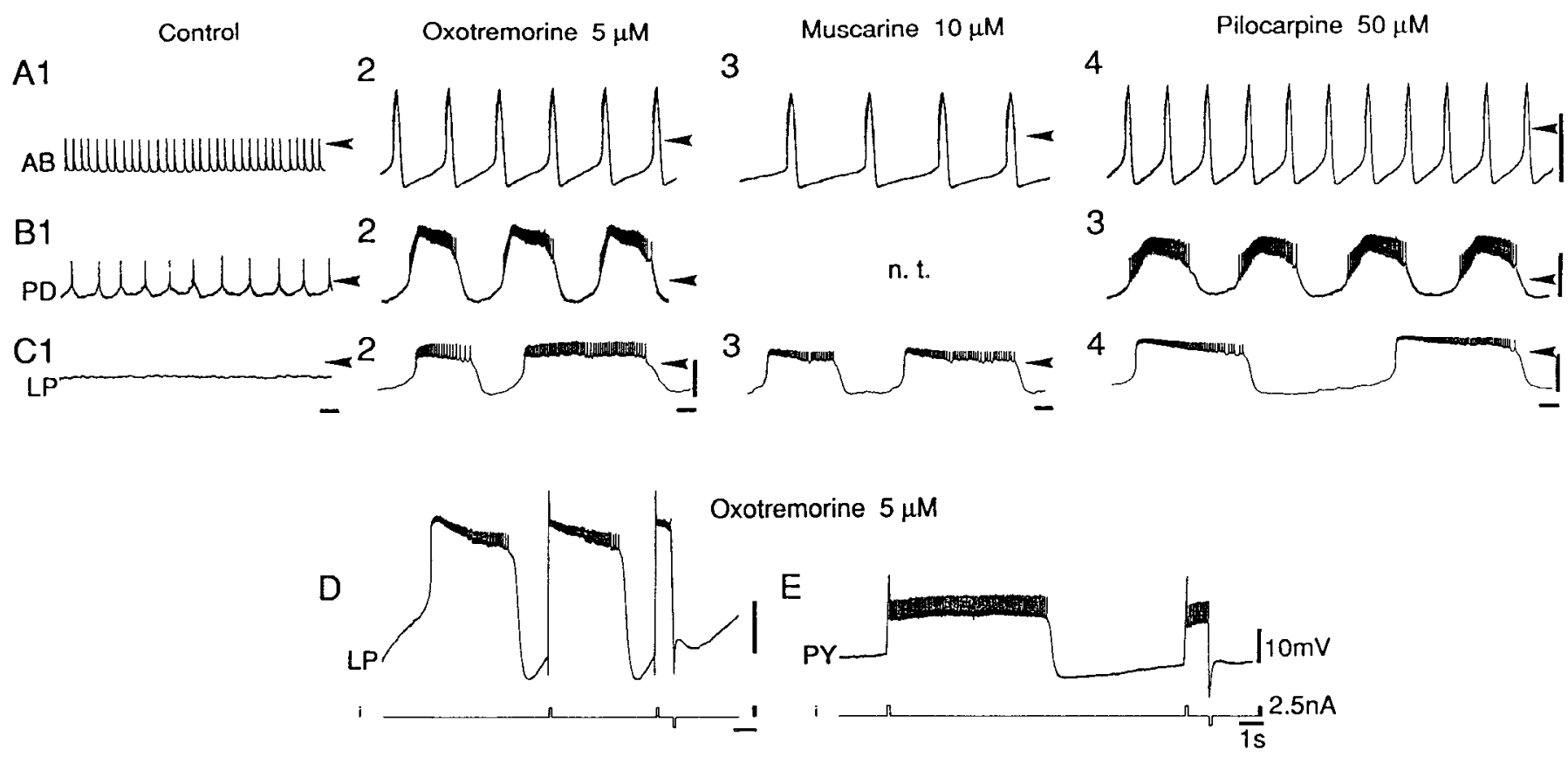

Figure 3. Muscarinic agonists induce oscillatory activity of the pyloric neurons isolated from the network and disconnected from anterior ganglia. $A-C$, The neurons $A B, P D$, and $L P$, respectively. 1 , Without modulator, the neurons fire tonically $(A B, P D)$ or are silent $(L P)$. 2-4, Muscarinic agonists $(2,5 \mu \mathrm{M}$ oxotremorine; $3,10 \mu \mathrm{M}$ muscarine; $4,50 \mu \mathrm{M}$ pilocarpine) switch the neurons to their bursting mode with characteristics that are specific to each neuron. Tips of the arrowheads indicate $-40 \mathrm{mV}$. $D$ and $E$, Bistability of the constrictor neurons under $5 \mu \mathrm{M}$ oxotremorine. Plateaus are triggered by depolarizing current pulses, and cut short by hyperpolarizing current pulses. All the neurons except $A B$ were maintained slightly hyperpolarized by current injection $(P D,-3 \mathrm{nA}$ in $B 2,-2 \mathrm{nA}$ in $B 3 ; L P,-1 \mathrm{nA}$ in $C 2,-2 \mathrm{nA}$ in $C 3$ and $C 4,-4.8 \mathrm{nA}$ in $D ; P Y,-1.4 \mathrm{nA}$ in $E$; sec text for explanations).

does not express any rhythmic activity, a pyloric rhythm may be evoked by stimulation of muscarinic receptors of the pyloric neurons. The modulatory action of oxotremorine alone is able to turn on and maintain an organized rhythmic pattern of the pyloric network with all its neurons fully active.

\section{Different types of oscillator revealed by muscarinic modulation}

One possible mechanism by which muscarinic receptor stimulation evokes rhythmicity in the pyloric circuit is the activation of rhythmogenic properties in the individual neurons. This possibility was tested after isolation of the pyloric neurons from each other, to prevent their specific response from being biased by the powerful synaptic interactions occurring in the intact network. The isolation in situ of a neuron was performed by selective photoinactivation of several of its presynaptic neurons, and pharmacological block of remaining synapses within the pyloric network (see Materials and Mcthods). The ncuron was also disconnected from extrinsic inputs by a sucrose block on the input nerve to the STG.

Under these experimental conditions, all isolated pyloric neurons switched their activity from a tonic mode of firing to a bursting mode under the action of muscarinic agonists (tested for 42 isolated neurons; $7 \mathrm{AB}, 8 \mathrm{PD}, 2 \mathrm{VD}, 11 \mathrm{LP}, 11 \mathrm{PY}$, and $3 \mathrm{IC}$ ). Figure $3 A-C$ illustrates the responses of the isolated neurons $\mathrm{AB}, \mathrm{PD}$, and $\mathrm{LP}$ to the classical muscarinic agonists oxotremorine, muscarine, and pilocarpine. To reveal their ability to oscillate, all the neurons except $A B$ had to be slightly hyperpolarized by constant current injection; once isolated and activated by muscarinic agonists, pyloric neurons were generally strongly depolarized and cannot cross spontaneously the threshold for regenerative repolarization (see Bal et al., 1988). It is clear that although the different types of pyloric neurons can be activated by the same agonist at the same concentration, the characteristics of their oscillatory activity remained different from each other (Fig. 3). The AB interneuron had the shortest burst duration and the shortest period of oscillation while the constrictor neurons produced long plateaus with the longest period, as shown for the LP neuron in Figure $3 C$. Rhythmic activity of the PD neuron had intermediate characteristics (measures of burst duration and period of oscillation are compared in Fig. 8).

Figure 3, $D$ and $E$, demonstrates that muscarinic agonists did not change only membrane potential, but induced regenerative properties of pyloric neurons. In the presence of oxotremorine, brief pulses of depolarizing current (labeled " $i$ ") triggered plateau potentials in a LP neuron (Fig. 3D) and a PY neuron (Fig. $3 E$ ), and these triggered plateaus were cut short by pulses of hyperpolarizing current. The same tests applied to the same isolated neurons in the absence of muscarinic agonists, evoked only passive responses of the neurons, while depolarizing or hyperpolarizing the neurons by passing direct current never generated oscillations (see Bal et al., 1988). With the exception of the VD neuron (see below), the types of regenerative property activated by muscarinic agonists, long repetitive plateaus or short oscillations, were similar to those displayed by the same neurons isolated from network but still connected to the anterior ganglia, and thus under the natural influence of modulatory inputs (see Bal et al., 1988).

The activation of oscillatory properties of the pyloric neurons by muscarinic agonists was specifically blocked by different muscarinic antagonists. Scopolamine $(5 \mu \mathrm{M})$, pirenzepine $(1 \mu \mathrm{M})$, and atropine $(60 \mu \mathrm{M})$ blocked muscarinic induced oscillations in all the tested neurons. This is shown in Figure $4, A$ and $B$, for the isolated VD neuron in two different experiments. Scopolamine 

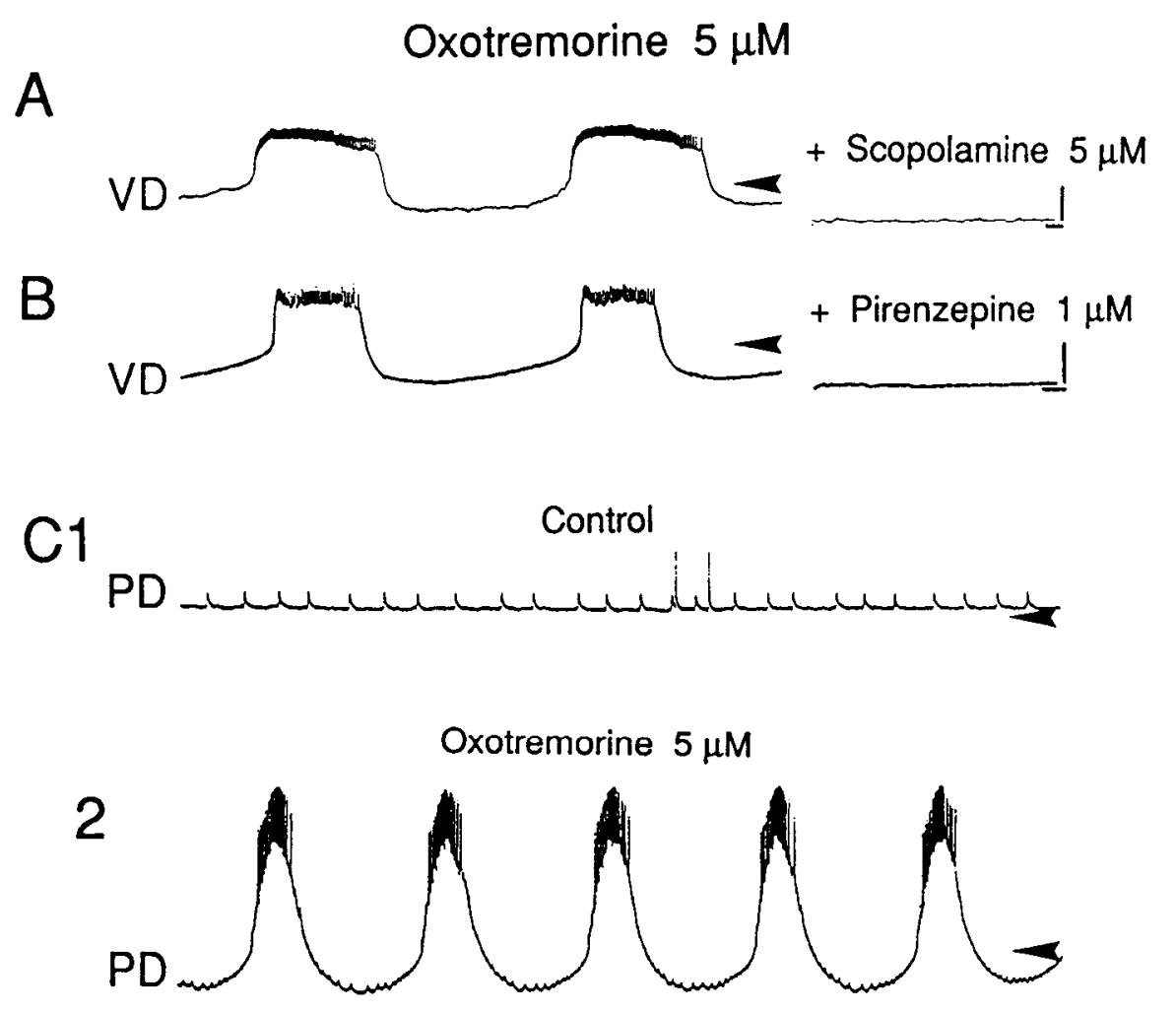

Figure 4. Oxotremorine induction of bursting in the pyloric neurons is reversed by muscarinic antagonists. $A$ and $B$, Bursting activity of the isolated VD neuron under $5 \mu \mathrm{M}$ oxotremorine is blocked by $5 \mu \mathrm{M}$ scopolamine $(A)$, and $1 \mu \mathrm{M}$ pirenzepine $(B) ; A$ and $B$ are from different experiments. $C$, Activation by oxotremorine of bursting in a PD neuron (electrically coupled to the other PD and the $\mathrm{AB}$ neuron) $(1,2)$ is not reversed by the nicotinic antagonist $d$-tubocurarine $(500 \mu \mathrm{M} ; 3)$, but is completely blocked by $60 \mu \mathrm{M}$ atropine (4). Small units in 1 and 4 are electrotonic potentials from $\mathrm{AB}$ spikes. Tips of the arrowheads indicate $-50 \mathrm{mV}$.

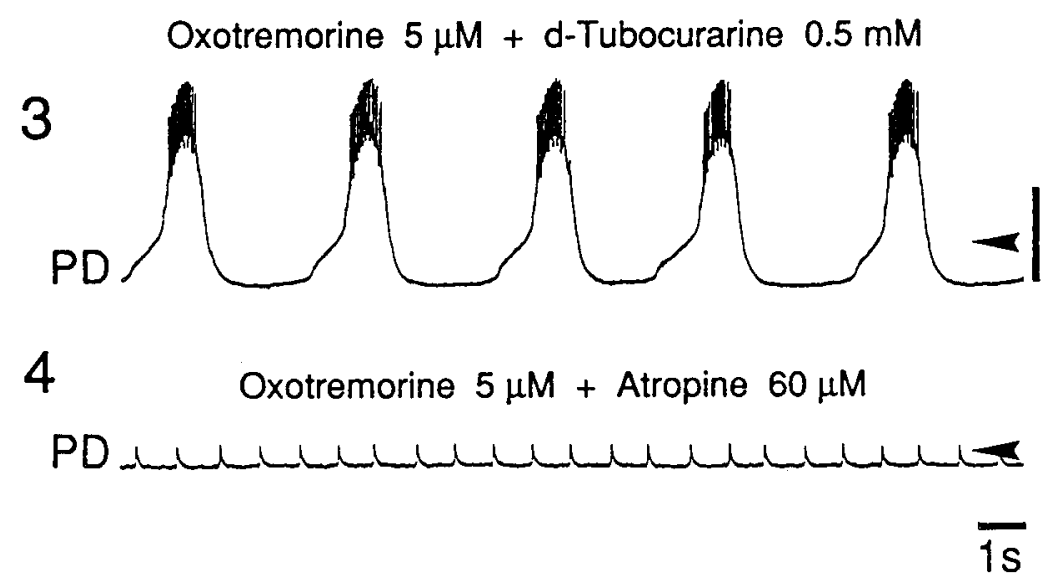

was also tested on two $\mathrm{AB}$, two PD, one VD, one PY, and four LP ncurons all isolated from network, and pirenzepine was tested on one isolated VD neuron and on one LP and two PD neurons in the intact network. However, application of the nicotinic antagonist $d$-tubocurarine did not suppress the oscillatory activity induced by a muscarinic agonist $(n=3$ neurons; Fig. $4 C$ ). In the experiment of Figure $4 C$, the two PD neurons electrically coupled with the $A B$ interneuron were isolated from the rest of the network (by blocking glutamatergic synapses with picrotoxin; see Materials and Methods), and disconnected from anterior ganglia. Under these experimental conditions the recorded PD neuron was mostly silent (Fig. $4 C_{l}$ ) and was switched to its bursting mode by oxotremorine (Fig. $4 C_{2}$ ). This bursting activity was not suppressed by $d$-tubocurarine at high concentration $(0.5 \mathrm{~mm})$ (Fig. $\left.4 C_{3}\right)$ but was blocked by atropine at much lower concentration $(60 \mu \mathrm{M})$ (Fig. $\left.4 C_{4}\right)$.

Taken altogether, these results suggest that stimulation of muscarinic receptors induces a specific endogenous rhythmic activity in each type of pyloric neuron. This was confirmed by comparing the different types of neurons under variable concentrations of muscarinic agonist and at different holding membrane potentials.

\section{Muscarinic modulation of oscillatory properties is dose} dependent

Activation of the oscillatory properties of the pyloric neurons is a function of oxotremorine concentration. This is shown by adding increasing concentrations of the agonist in the bath solution of a STG disconnected from anterior ganglia (Fig. 5). In Figure $5 \mathrm{~A}$, the activity of the AB-PD group, isolated from the other neurons of the network, was monitored in a PD neuron. Most of the parameters that describe their activity (period and amplitude of oscillation, frequency of discharge) changed progressively with the concentration of oxotremorine. Oscillations 
A1 Oxotremorine $0.25 \mu \mathrm{M}$

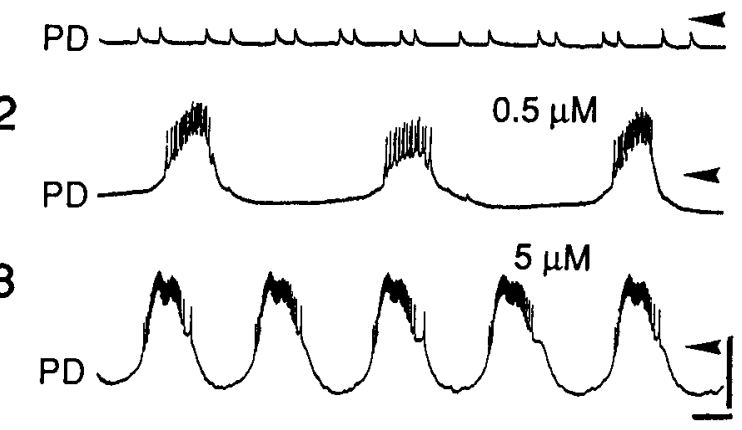

B1 Oxotremorine $0.1 \mu \mathrm{M}$

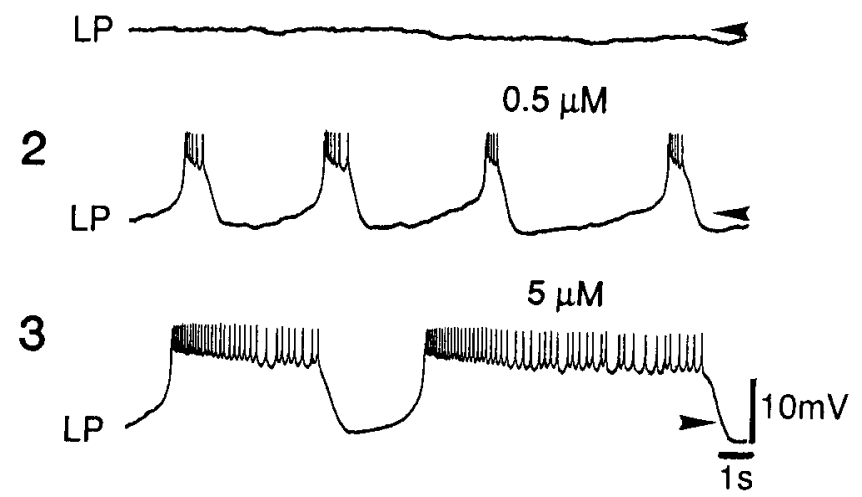

Figure 5. Oxotremorine activation of bursting properties of the pyloric neurons is dose dependent. $A$, Pacemaker $P D$ neuron (electrically coupled to the $\mathrm{AB}$ interneuron and the other $\mathrm{PD}$ neuron). $B$, Constrictor LP neuron. Threshold for oxotremorine is above $250 \mathrm{nM}$ for the PD neuron $\left(A_{2}\right)$ and above $100 \mathrm{nM}$ for the LP neuron $\left(B_{2}\right)$. As the concentration increases the bursting is enhanced $\left(A_{3}, B_{3}\right)$. The LP neuron was slightly hyperpolarized by current injection $(-2 \mathrm{nA})$, while the PD neuron was not. Tips of the arrowheads indicate $-40 \mathrm{mV}$ in $A$ and -50 $\mathrm{mV}$ in $B$.

appeared at $0.5 \mu \mathrm{M}$ oxotremorine. The oscillation period of the AB-PD group progressively decreased as the concentration of the agonist increased (Fig. $6 A$, circles; $n=3$ neurons) while the burst duration remained constant (Fig. $6 B$, circles; $n=3$ neurons). The oscillation parameters of the constrictor motor neurons also changed in a dose-dependent manner with oxotremorine (Fig. $5 B$; isolated LP neuron), but for some parameters the variation was in the opposite direction compared with the $\Lambda B-P D$ neurons. For instance, the oscillation period of an isolated LP neuron increased with increasing oxotremorine (Fig. $6 A$, triangles) while it decreased for the AB-PD neurons (Fig. $6 A$, circles). This increase in constrictor neuron period was accompanied by a parallel increase in burst duration. As shown in Figures $5 B$ and $6 B$, the burst duration of an isolated LP neuron rapidly lengthened with higher concentrations of oxotremorine (Figs. 5B; 6B, triangles). This increase in duration delayed the next oscillation and thus prolonged the oscillation period.

As mentioned previously (see Fig. 3), it was necessary to hyperpolarize slightly the isolated LP neuron by current injection in order to reveal its oscillatory activity $(-2 \mathrm{nA}$ in Figs. $5 B, 6 A, B)$. To make sure that this modification of membrane potential did not bias the dose dependence of muscarinic-induced oscillations, we measured the oscillation period of an
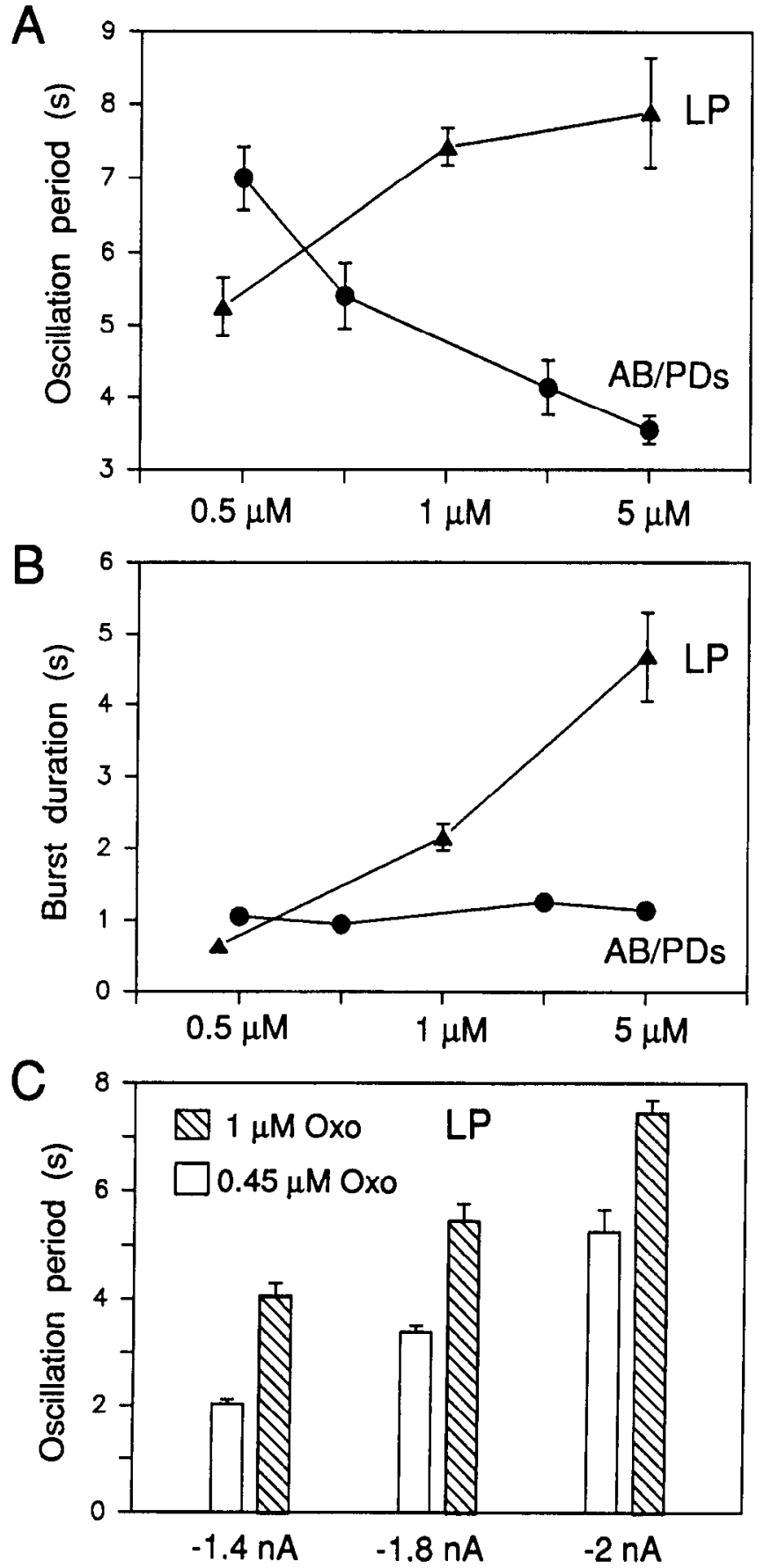

Figure 6. Differences in bursting activity of the pacemaker neurons $\mathrm{AB}-\mathrm{PD}$ and the constrictor neuron LP in response to increasing concentrations of the muscarinic agonist oxotremorine. $A$, Burst period versus oxotremorine concentration for the $\mathrm{AB}-\mathrm{PD}$ neurons (circles) and the LP neuron (triangles). $B$, Burst duration of AB-PD neuron (circles) and LP neuron (triangles) versus oxotremorine concentration. In $A$ and $B$ the LP neuron was slightly hyperpolarized by current injection $(-2$ nA). $C$, Burst period of the LP neuron at different intensities of injected hyperpolarizing current, during $0.45 \mu \mathrm{M}$ and $1 \mu \mathrm{M}$ oxotremorine. Burst periods are significantly different at any intensity of injected current $(P$ $<10^{-3}$, Student's $t$ test). Each point or column is a mean $\pm \operatorname{SD}(n=$ 30 for AB-PD, and $n=20-30$ for LP).

isolated LP neuron under two concentrations of oxotremorine $(0.45 \mu \mathrm{M}$ and $1 \mu \mathrm{M})$ for different intensities of injected current $(-1.4,-1.8$, and $-2 \mathrm{nA}$, Fig. $6 \mathrm{C})$. At any of the three different holding potentials, the oscillation period of the LP neuron sig- 


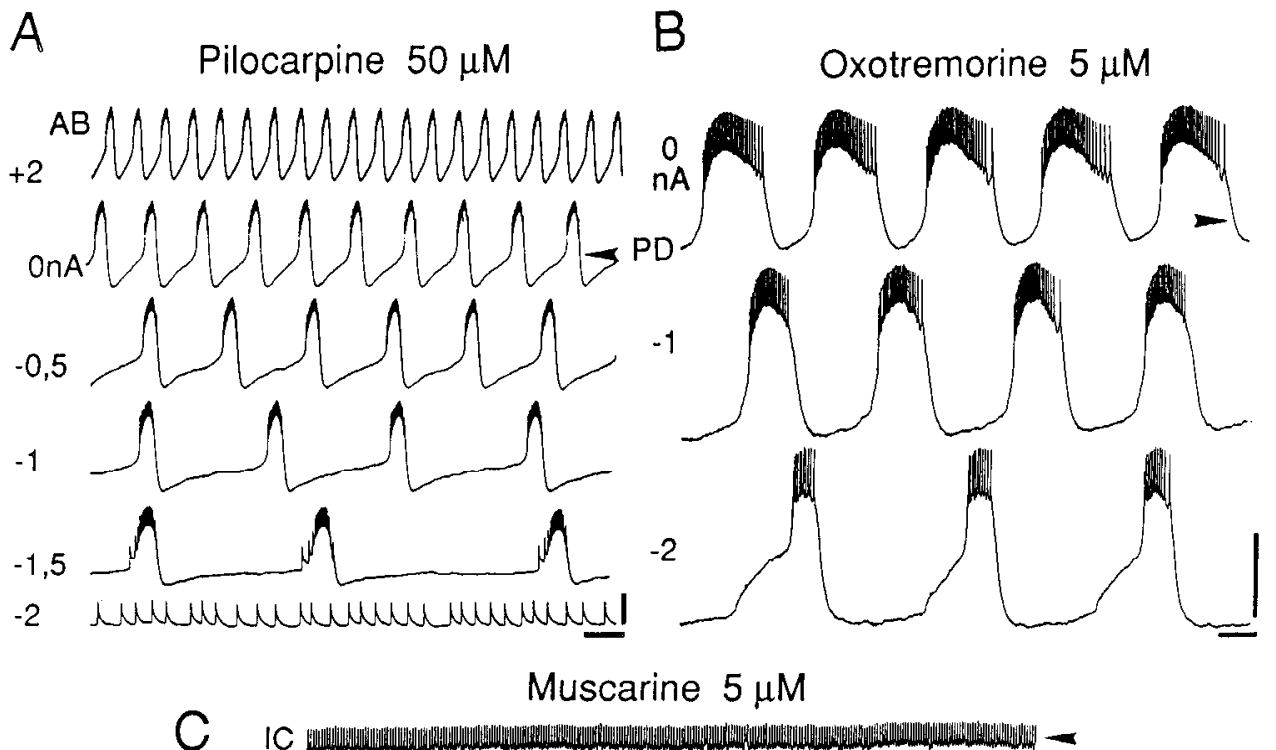

Figure 7. The oscillatory activity of isolated pyloric neurons under muscarinic modulation is voltage dependent. The AB, PD, and LP neurons are isolated from network and disconnected from anterior ganglia, and are superfused respectively by $50 \mu \mathrm{M}$ pilocarpine $(A), 5 \mu \mathrm{M}$ oxotremorine $(B)$, and $5 \mu \mathrm{M}$ muscarine $(C)$. The different traces correspond to different intensities of injected current. Tips of the arrowheads indicate $-50 \mathrm{mV}$ in $A$ and $B$, and -30 $\mathrm{mV}$ in $C$.

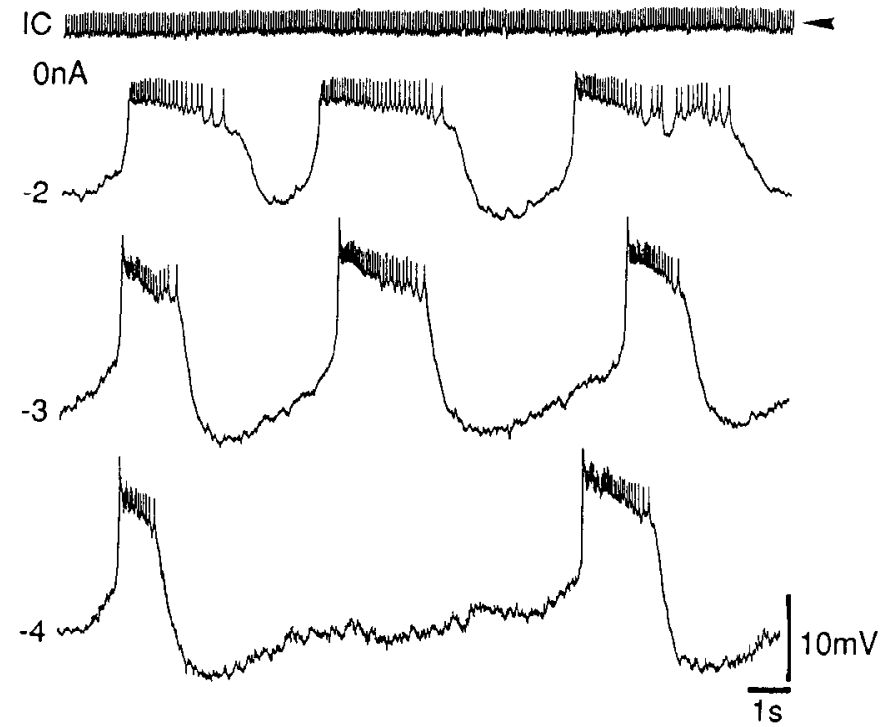

nificantly lengthened when the concentration of oxotremorine was increased. The threshold concentration for oxotremorine induction of oscillatory activity in the pyloric neurons was between $0.1 \mu \mathrm{M}$ and $0.5 \mu \mathrm{M}$. Compared to oxotremorine, muscarine and pilocarpine had a higher threshold of about $5 \mu \mathrm{M}$, but their effect on the pyloric neurons were identical.

The preceding results indicate first that muscarinic agonists evoke oscillatory behavior in the pyloric neurons, whose characteristics vary strongly with the concentration of the muscarinic agonist, and second that the pyloric neurons are intrinsically different from each other in their response to increasing concentrations of the agonist.

\section{Oscillatory activities in pyloric neurons at different membrane} potentials

Application of any of the muscarinic agonists at a concentration higher than the threshold for activation of oscillatory activity results in robust bursting of the isolated pyloric neurons which can be analyzed at various membrane potentials. This is shown in Figure 7 for the AB interneuron, the PD dilator motor neuron, and the IC constrictor motor neuron. The period and amplitude of their oscillations changed continuously with the membrane potential. However, differences appeared in the parameters of their oscillation. At resting membrane potential (no current injection), the $\mathrm{AB}$ interneuron oscillated spontaneously with a period ranging between 1 and $3 \mathrm{sec}$ ( $n=7$ of 7 neurons; Fig. $7 A, 0 \mathrm{nA})$. Conversely, only $20 \%$ of the PD neurons spontaneously oscillated with no current injection ( $n=1$ of 5 neurons; Fig. $7 B, 0 \mathrm{nA}$ ), and the oscillation period was then $2.86 \pm 0.06$ $\sec (n=30)$. In the remaining cases, the PD neuron fired tonically and had to be hyperpolarized by current injection to uncover its oscillatory activity. The other pyloric neurons, the VD neuron and the constrictor neurons LP, PY, and IC, were always tonically active when not hyperpolarized. This is shown in Figure $7 C(0 \mathrm{nA})$ for an isolated IC neuron.

Injections of steady current steps reveal important differences in oscillatory activity among the isolated pyloric neurons. The oscillation amplitude of the $\mathrm{AB}$ interneuron decreased slightly with both depolarization and hyperpolarization (Figs. $7 A ; 8 A_{l}$, circles). The burst duration of the $\mathrm{AB}$ interneuron slightly increased with hyperpolarization (Fig. $8 A_{i}$, triangles) while its oscillation period clearly increased continuously (Fig. $8 A_{2}$ ). The constrictor neurons (LP, PY, and IC) behaved differently when their membrane potential was modified. As shown for the IC neuron, the oscillation amplitude increased with hyperpolarization (Fig. $8 B_{l}$, circles) and burst duration decreased (Fig. $8 B_{l}$, 
AB Pilocarpine $50 \mu \mathrm{M}$
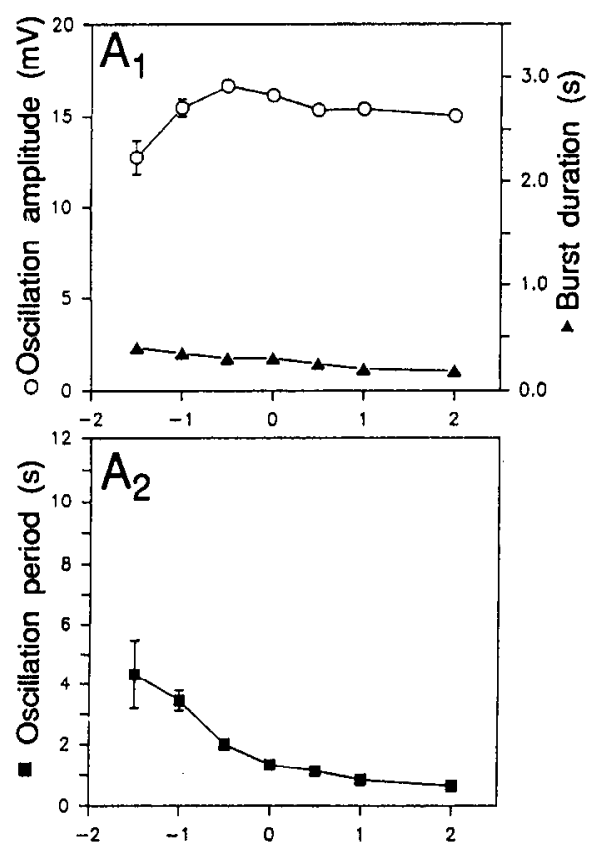

IC Muscarine $5 \mu \mathrm{M}$
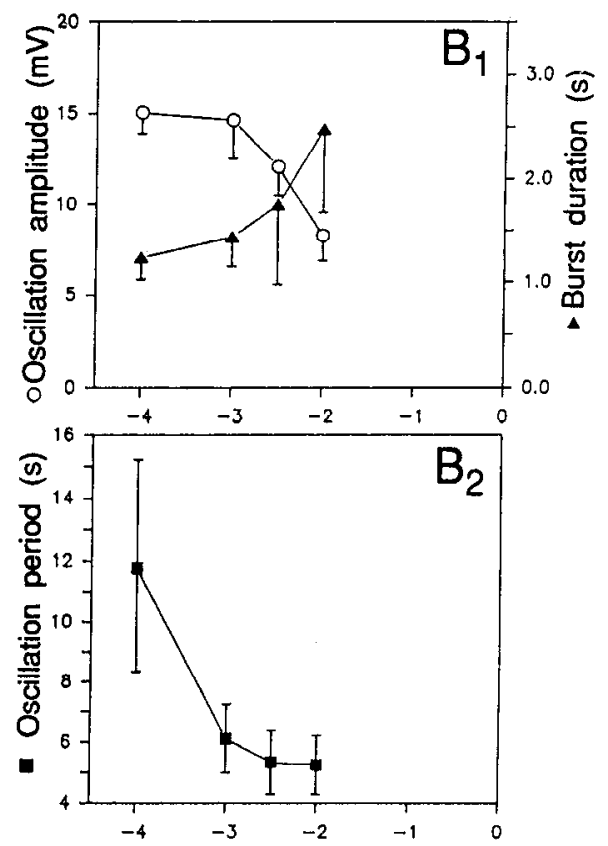

Figure 8. Differences in bursting activity of the pacemaker neuron $\mathrm{AB}$ and the constrictor neuron IC during muscarinic modulation as a function of membrane potential. $A, \mathrm{AB}$ neuron under experimental conditions of Figure $7 A$. Amplitude of oscillation $\left(A_{1}, \mathrm{Cir}\right.$ cles), burst duration ( $A_{1}$, triangles), and burst period $\left(A_{2}\right)$ are plotted versus intensity of current injected in the soma of $\mathrm{AB}$; each point is a mean $\pm \mathrm{SD}, n=$ 30 , for a single $\mathrm{AB}$ neuron. $B$, IC neuron under experimental conditions of Figure $7 B$. Each point is a mean $\pm \mathrm{SD}, n$ $=20-30$, for a single IC neuron. triangles). Moreover, the parameters of oscillation of the constrictor neurons were much more variable than those of the dilator neurons and of the $\mathrm{AB}$ interneuron (compare the SDs in Fig. $8 A, B$ ). Again, it is worth noting that isolated pyloric neurons disconnected from anterior ganglia and activated by muscarinic agonists react to modifications of their membrane potential in a way similar to that when the same neurons are connected to the anterior ganglia (Bal et al., 1988; see Discussion).

An exception, however, is the isolated VD neuron, which had very different oscillatory behavior when modulated by neuronal inputs from anterior ganglia, or stimulated by a muscarinic agonist. When the VD ncuron was isolated from the pyloric network but was still connected to the anterior ganglia, it behaved like a rapid oscillator (Fig. $9 \mathrm{~A}$ ) with a mean period intermediate between that of the isolated $\mathrm{AB}$ interneuron and the isolated PD neuron: $\mathrm{AB}=0.77 \pm 0.09 \mathrm{sec}<\mathrm{VD}=0.88 \pm$ $0.37 \mathrm{sec}<\mathrm{PD}=1.09 \pm 0.23 \mathrm{sec}$ (data from Bal et al., 1988, with no current injection). Conversely, an isolated VD neuron disconnected from the anterior ganglia was turned into a slow oscillator by stimulation of its muscarinic receptors and hyperpolarization (Fig. $9 B$ ). In these conditions, the oscillation period $(12.4 \pm 0.4 \mathrm{sec}, n=13)$ and burst duration $(3.14 \pm 0.4 \mathrm{sec}, n$ $=14$ ) of the VD neuron were stable and very different from those in the control conditions (Fig. $9 A$; period $=1.3 \pm 0.14$ sec, $n=30$, and duration $=0.21 \pm 0.03 \mathrm{sec}, n=30$ ). As

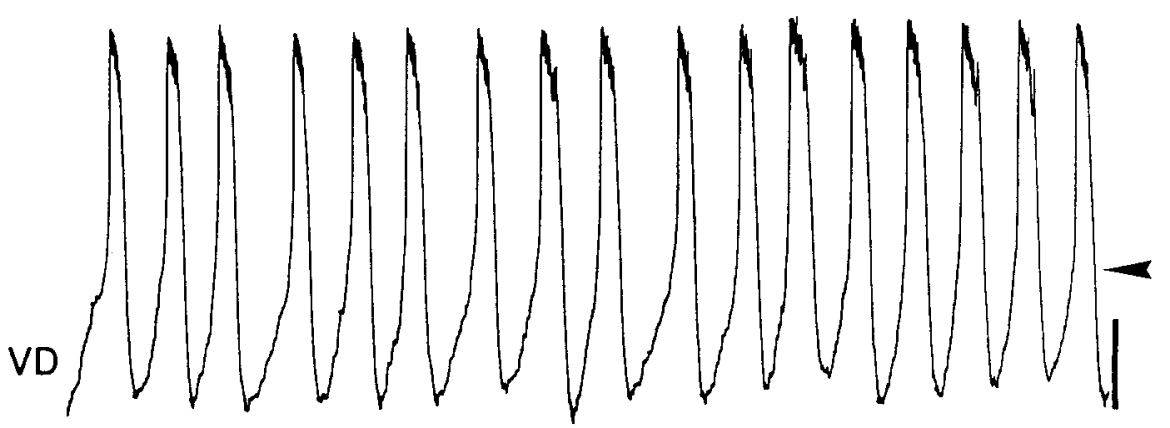

B

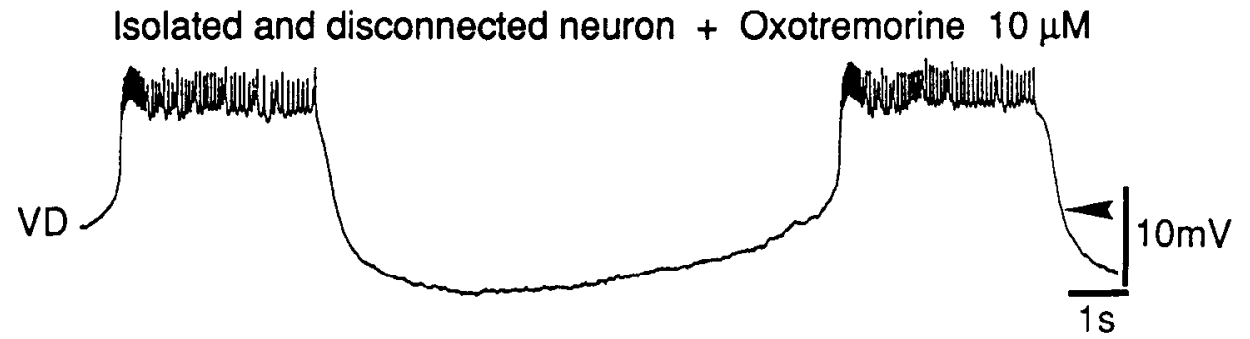

Figure 9. Oxotremorine evokes different oscillatory properties in VD than descending input from anterior ganglia. $A$, When isolated from the network but connected to anterior ganglia, the VD neuron oscillates at approximately $1 \mathrm{~Hz}$. $B$, When disconnected from anterior ganglia and bathed with $10 \mu \mathrm{M}$ oxotremorine, the oscillation period and burst duration of the VD neuron are much longer. In $A$ and $B$, the VD neuron is hyperpolarized by current injection ( -4 $\mathrm{nA})$. Tips of the arrowheads indicate $-50 \mathrm{mV}$. 
described above, during muscarinic stimulation the VD neuron must be hyperpolarized by current injection in order to oscillate $(-4 \mathrm{nA}$ in Fig. 9B). For comparison, the VD neuron in the control conditions (Fig. $9 A$ ) was hyperpolarized by the same amount of current. Similar results were observed in six other preparations (see, e.g., Fig. $4 A$ ).

Thus, our data lead to the conclusions that (1) each pyloric neuron presents a specific oscillatory behavior when their muscarinic receptors are stimulated, (2) this behavior is of same type (long plateaus, fast or slow oscillations; same sensitivity to modifications in membrane potential) as that seen in the same neurons when modulated by inputs from the anterior ganglia, and (3) for the VD neuron, the oscillatory behavior differs strongly depending on the modulatory influence it receives. The role that these differences in oscillatory activity play in the generation of the final pattern of the network is examined in the following section.

\section{Reconstruction of the synaptic network under muscarinic stimulation}

In order to understand the functional consequences of muscarinic stimulation at the level of the network as a whole, data obtained from isolated cells may be compared with those obtained with different portions of the network, comprising increasing numbers of interconnected neurons. By doing so, the modification of one neuron's activity by the other neurons can be explained. A progressive reconstruction of the network could be achieved by first reestablishing the synaptic connections between two neurons and then by adding progressively more neurons to this subset. For technical reasons, the strategy was revcrscd, and neurons were progressively deleted from the network by the photoinactivation technique.

Synaptic interactions between neurons in the pyloric network are of two types, electrical and chemical. In a first step, the influence of electrical synapses was tested by progressive reconstruction of a subset of electrically coupled neurons comprised of the pacemaker group (AB and PD) and the VD neuron (Fig. $10)$. The intrinsically different oscillatory properties of the isolated $\mathrm{AB}, \mathrm{PD}$, and $\mathrm{VD}$ neurons under the same muscarinic influence ( $5 \mu \mathrm{M}$ oxotremorine) is recalled in Figure $10 \mathrm{~A}-\mathrm{C}$. Spontaneous activity of an isolated PD neuron is rather variable from one experiment to the next and, as already mentioned, generally requires a slight hyperpolarization to be expressed. It is therefore difficult to compare with the activity of PD when coupled to the $A B$ neuron. When coupled to $A B$, however, $P D$ always oscillates spontaneously without injection of hyperpolarizing current, and their synchronized burst durations are shorter than PD alone (compare AB-PD coupled in Fig. 10D with PD isolated in Fig. $10 B$; burst duration is, respectively, mean $\pm \mathrm{SD}=0.55$ $\pm 0.06 \mathrm{sec}, n=60$, and $1.6 \pm 0.12 \mathrm{sec}, n=60)$. This is in any case longer than burst duration of the isolated $\mathrm{AB}$ neuron $(0.3$ $\pm 0.02 \mathrm{sec}$ ). Much more drastic modifications arose when the VD neuron was added to the coupled AB-PD neurons (Fig. $10 E, F)$. This step of the rcconstruction was achieved by blocking all the glutamatergic synapses in the intact network with picrotoxin. The oscillatory activity of the resulting AB-PD-VD subset of neurons was recorded in a PD neuron (Fig. 10E) and a VD neuron (Fig. 10F) in two different experiments with the same concentration of oxotremorine. First, when coupled with the AB-PD group, the VD neuron was maintained in a range of membrane potential where it can oscillate, whereas when isolated the VD neuron remained depolarized, fired tonically at high frequency, and cannot oscillate spontaneously unless hyperpolarized by current injection (see above). Second, the PD activity had a hybrid rhythm made of short periods of oscillation repetitively interrupted by longer and more deeply hyperpolarized periods (Fig. 10E). Similarly, the slow oscillations of the VD neuron separated by long hyperpolarizations (Fig. 10F) were shaped by rapid oscillations and high frequency firing. Comparing Figure $10, E$ and $F$, it appears that the long hyperpolarized periods of the $\mathrm{PD}-\mathrm{AB}$ group corresponds to the interburst intervals of the VD intrinsic rhythm, while the fast oscillations on top of the VD plateaus correspond to the intrinsic oscillations of the AB-PD group. This is shown more clearly in Figure $10 G$ with the distribution histograms of the burst periods recorded in PD and VD. In Figure 10G, burst periods were recorded in $\mathrm{PD}$ when coupled with $\mathrm{AB}$ (experimental conditions of Fig. $10 D$ ), and in Figure $10 G_{2}$ when coupled with $\mathrm{AB}$ and VD (experimental conditions of Fig. $10 E$ ); in Figure $10 G_{3}$, burst periods were recorded in VD when coupled with $\mathrm{PD}$ and $\mathrm{AB}$ (experimental conditions of Fig. $10 F$ ). Without VD, burst periods of the pacemaker group were distributed in a single peak, while in the presence of VD the distribution was bimodal. Note that the intervals between the intrinsic plateaus of the VD neuron may be variable, which flattened the second peak in Figure $10 G_{2}$, and was somewhat different in the experiment shown in Figure $10 G_{3}$. The first peaks, however, were similar in Figure 10, $G_{2}$ and $G_{3}$, suggesting that the intrinsic activity of the PD-AB group was similar in the two experiments.

These results demonstrate that the oscillatory behavior of a given pyloric neuron, under the influence of a single modulator, significantly affects the activity of other neurons via their electrical coupling. The AB-PD-VD subset of neurons under muscarinic modulation integrates instantaneously the intrinsic oscillatory behavior of its components and releases an original hybrid pattern that none of the components were able to create alone.

Finally, keeping the constrictor neurons (LP, PY, and IC) together with the AB-PD-VD subset, that is, reconstructing the entire pyloric network, sheds some light on the action of the inhibitory synaptic connections within the pyloric network when modulated by muscarinic agonists. As already mentioned, the pyloric network displayed a stable triphasic pattern when disconnected from the anterior centers and modulated by saturating concentrations of a muscarinic agonist (Fig. $1 E, 10 \mu \mathrm{M}$; Fig. $2 D, 1 \mu \mathrm{M})$. With lower concentrations of the modulator, however, the pyloric network produced more variable patterns depending on the preparation and the concentration of the muscarinic agonist (see Fig. 2, and Discussion).

Figure 11 shows a pattern produced by the pyloric network in the same experiment as Figure 1, but for a lower concentration of oxotremorine $(5 \mu \mathrm{M})$. A remarkable feature of this spontaneous pyloric activity was the alternation of two different bursting periods of the $A B / P D$ neurons (Fig. 11; large unit in the stn), which oscillated only during prolonged plateaus of the VD neuron. Thus, within the intact pyloric network under muscarinic stimulation, the AB-PD-VD group of neurons can produce a hybrid activity similar to the one produced when the group is isolated. The pattern of the entire network was influenced in turn by this hybrid activity of the AB-PD-VD group, with the constrictor neurons LP and PY bursting with two different periods. Another interesting feature of this pattern is that the influence of the AB-PD group was less than when the pyloric network was connected to the anterior centers. In the normal 

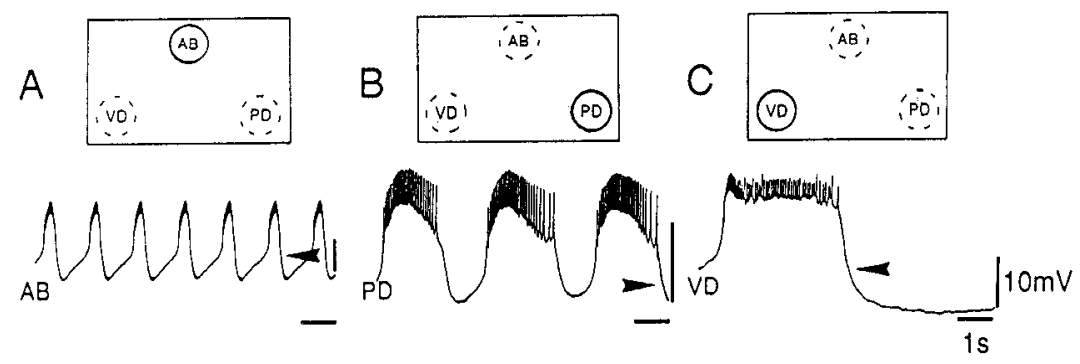
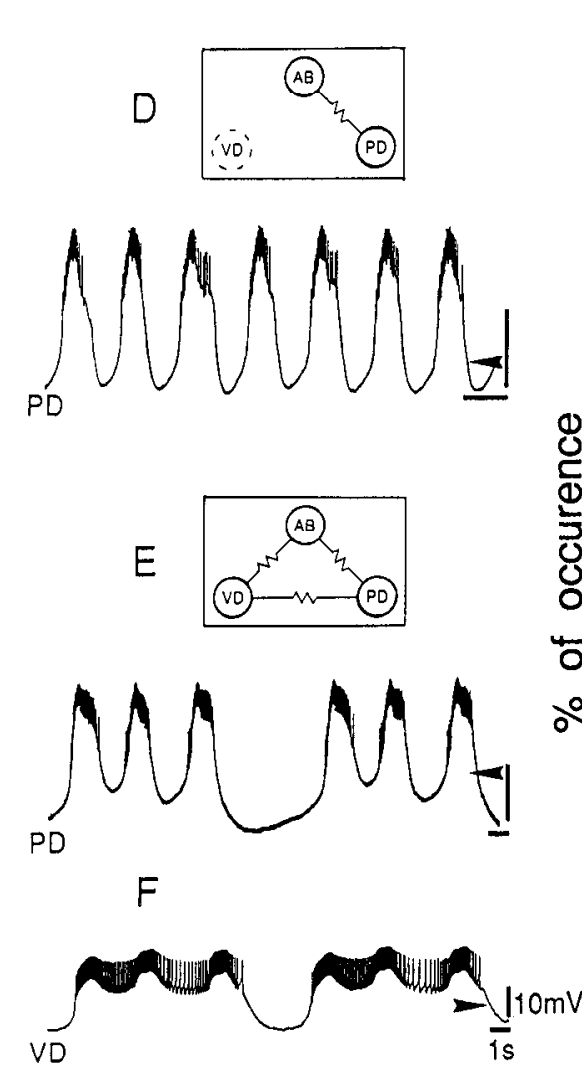
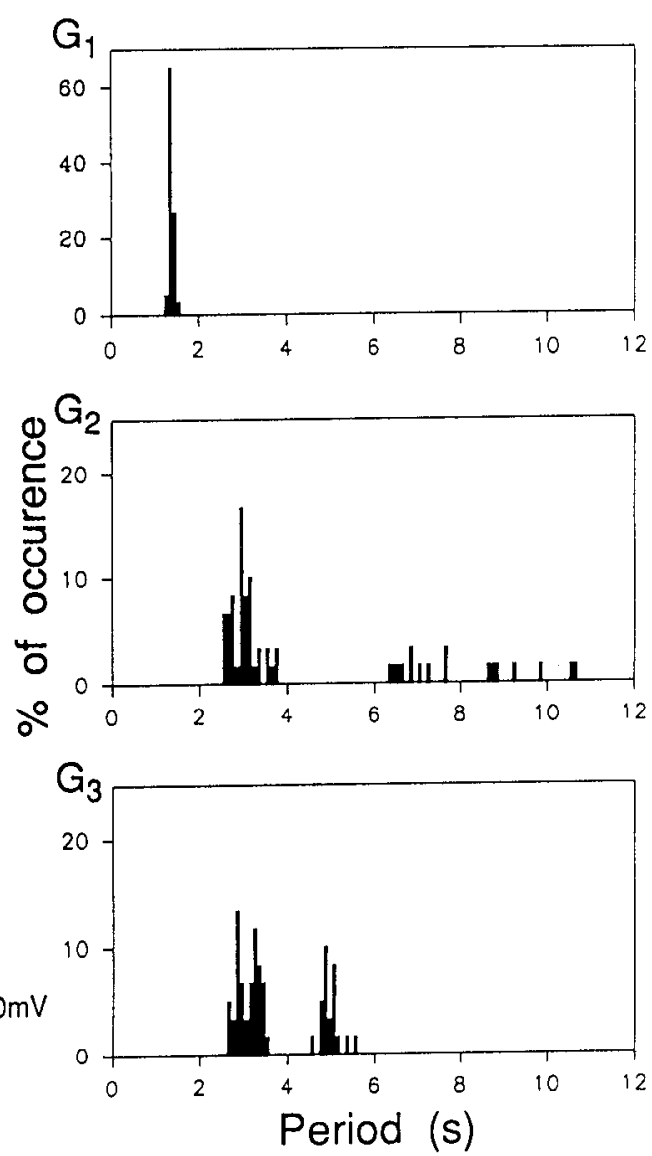

Figure 10. Three different and electrically coupled oscillators form a "composite pacemaker" during muscarinic modulation. $A-F$, STG disconnected from anterior ganglia and bathed with $10 \mu \mathrm{M}$ picrotoxin (to block glutamatergic synapses) and $5 \mu \mathrm{M}$ oxotremorine. Diagrams represent the recorded pyloric neurons and their connections (taken from different preparations). The cells and connections left intact are shown in continuous circles; the cells shown in dashed circles have been deleted from the circuit by photoinactivation. Resistance symbol, electrical synapse. $A-C$, Spontaneous activity of the $A B, P D$, and $V D$ neurons fully isolated from network (VD is hyperpolarized by $-4 \mathrm{nA}$ ). $D$, Activity of the coupled AB-PD neurons recorded in onc PD. E, Activity of the coupled AB-PDVD neurons recorded in one PD. Oscillations are grouped in triplets. $F$, Complex rhythmic activity recorded in the VD neuron when coupled to the $A B$ and PD neurons. $G$, Distribution histograms of the oscillation periods of a PD neuron $\left(G_{1}, G_{2}\right)$ under the experimental conditions of $D$ and $E$, respectively, and of the VD neuron $\left(G_{3}\right)$ under the experimental conditions of $F ; n=$ 60 for each histogram (see text for comments). Tips of the arrowheads indicate $-50 \mathrm{mV}$. situation, the $\mathrm{AB}$ and $\mathrm{PD}$ neurons are the pacemakers of the pyloric rhythm, and they rhythmically inhibit and repolarize the bursts of the other neurons. This was no longer the case for the VD neuron when the pyloric network was disconnected from anterior ganglia and modulated by low concentrations of a muscarinic agonist. Figurc 11 shows that the VD bursts were no longer terminated by the synaptic inhibition from the AB neuron (open arrows), but were then terminated by the synaptic inhibition from the LP neuron (solid arrows). This insensitivity of $\mathrm{VD}$ firing to inhibition from the $\mathrm{AB}$ neuron also occurred in strong and regular pyloric patterns induced by higher doses of muscarinic agonist (see Fig. $1 E$ ). In addition, the LP bursts, which are normally terminated by the PY neurons were then interrupted instead by the high frequency firing of the VD neuron (arrowheads). It is clear, therefore, that the relative importance of the synapses in the network was modified under muscarinic modulation.

Figure 12 shows that patterns produced by the network under single muscarinic influence at low doses, can be very sensitive to modification of membrane potential in individual neurons. In the experiment of Figure $12 \mathrm{~A}$, where the intact pyloric net- work was disconnected from anterior centers and superfused with $5 \mu \mathrm{M}$ oxotremorine, the activity of the network was disorganized (Fig. 12A, left). The period, burst duration, and oscillation amplitude of the PD, LP and PY neurons were unstable. When the LP neuron was hyperpolarized with current injection (Fig. 12A, dashed line; $2 \mathrm{nA}$ ) a very strong and regular triphasic rhythm immediately appeared that lasted as long as the hyperpolarization was maintained. In another preparation but under the same experimental conditions, the activity of the pyloric network was almost tonic and rather irregular (Fig. 12 $B_{l}$ ). Again, constant hyperpolarization of the LP neuron (Fig. 12B, dashed line; $-4 \mathrm{nA}$ ) evoked a triphasic pyloric pattern with the neurons fully active. Therefore, under moderate muscarinic modulation, a slight modification in membrane potential of a single neuron can induce a drastic change in its own activity and switch the entire pyloric network to a completely different pattern.

\section{Discussion}

The operation of the pyloric network is highly flexible and strongly depends on the control exerted by a number of modulatory inputs (Harris-Warrick and Marder, 1991; Harris-War- 


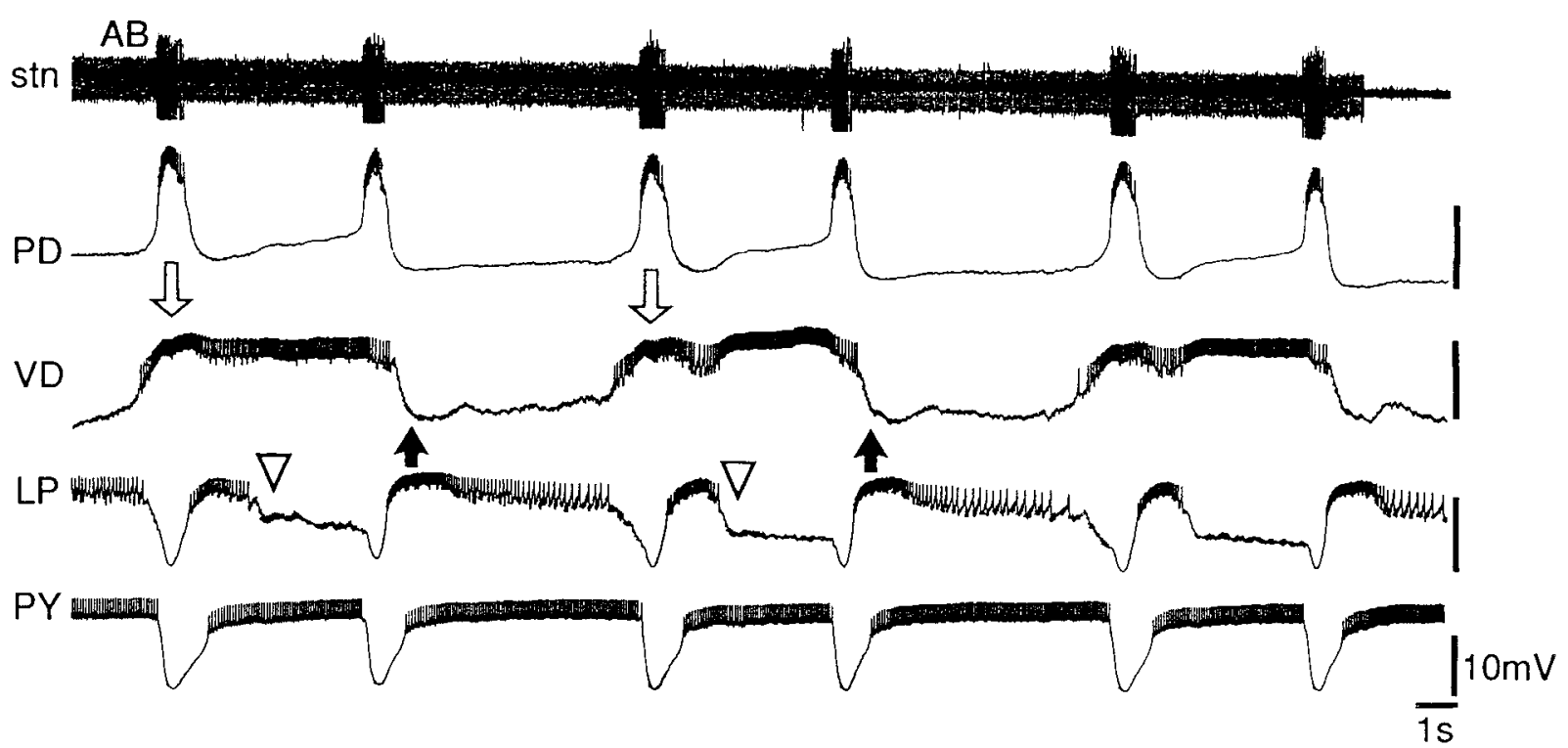

Figure 11. The muscarinic agonist oxotremorine may induce a complex pyloric pattern (compare with Fig. $1 C$ ). The pyloric network is intact. The STG is disconnected from anterior ganglia and bathed with $5 \mu \mathrm{M}$ oxotremorine. Extracellular recording: $\sin (A B)$; intracellular recordings: $P D$, $V D, L P$, and $P Y$. Solid arrows, inhibition of the VD neuron by the LP neuron; arrowheads, inhibition of the LP neuron by the VD neuron; open arrows, lack of inhibition of the VD neuron by the AB and PD neurons.

rick et al., 1992b; Nagy et al., 1992). In addition, it is composed of neurons that are all oscillators, but with heterogeneous characteristics of oscillation (Bal et al., 1988). In other words, the flexibility of the pyloric network output depends on the integration of various modulatory influences by heterogeneous neuronal oscillators. This can lead to a large number of potential combinations, with many possibilities of output, rather difficult to analyze experimentally. A simplified approach started by Marder and Eisen (1984) was to study the action of a single modulator on a number of isolated pyloric neurons in order to understand the modulator action on the intact network. In the present article we extended this type of analysis to all pyloric neurons isolated from network interactions, and subjected only to pharmacological stimulation of their muscarinic receptors. As a first stcp, we demonstrated that all the neurons of the pyloric network are sensitive to the modulatory action of either muscarine, oxotremorine, and pilocarpine, and that each pyloric neuron produces a specific oscillatory behavior under the influence of these muscarinic agonists. We have shown how the individual regenerative behavior of the neurons, evoked by muscarinic agonists, is shaped and integrated by the synaptic connectivity of the pyloric network to generate a motor pattern. In addition, our analysis confirmed and extended the notion that the pacemaker function can be carried by different neurons depending on the modulatory input controlling the network. Before considering these findings for discussion, we must address the question of the relevance of a prolonged bath application of a single modulatory substance to understanding the mechanisms underlying control by natural modulatory inputs.

\section{Relevance of single modulatory stimulation}

A first drawback of the pharmacological approach is that it eliminates the temporal characteristics of discharge of the natural modulators. With the pyloric network, however, this is not too unrealistic for two reasons. First, a paramount characteristic of its operation is a tight dependency on continuous neurotransmitter release by modulatory pathways descending from the anterior ganglia (Russell, 1979; Moulins and Cournil, 1982; Nagy and Miller, 1987; Bal et al., 1988). Second, humoral modulatory influences seem to act in parallel with the neural modulation to maintain the rhythmic activity of the pyloric network (Beltz et al., 1984; Rezer and Moulins, 1992).

Bath application of a modulatory substance has a second potential drawback compared with stimulation of a neuronal input, which is a general stimulation of all the neurons of the target network that have the appropriate receptors, instead of a specific distribution of input connections. This general activation, however, is reminiscent of the modulatory control by the APM neuron (Nagy and Dickinson, 1983), which is presumably cholinergic and can activate the pyloric network by promoting rhythmogenic properties of all the pyloric neurons (Bal, 1991).

Despite their inherent limitations, however, our simplified experimental conditions allowed a good control of the modulatory stimulation, and permitted us to reveal intrinsic differences in active properties and in sensitivity to the modulator among the target neurons.

\section{Muscarinic modulation and isolated neurons}

Due to complex synaptic interactions within the pyloric circuit, a neuron can react quite differently to a modulator whether in the intact network or isolated in situ from its partners. For instance dopaminergic modulation results in excitation of the PD and VD neurons in the intact network (Flamm and HarrisWarrick, 1986a), although dopamine directly inhibits the two neurons (Flamm and Harris-Warrick, 1986b), and the peptide proctolin activates bursting activity of the PD neuron in the intact network, although it does not induce any direct effect on this neuron (Hooper and Marder, 1987). Similarly, the modulatory neuron PS directly activates the isolated AB neuron (Cazalets et al., 1990b), whereas evoking a long-lasting inhibition of $\mathrm{AB}$ in the intact network (Cazalets et al., 1990a). Clearly, comprehensive study of the action of a modulator on the pyloric circuit must include analysis of the modulatory effect on isolated neurons. 

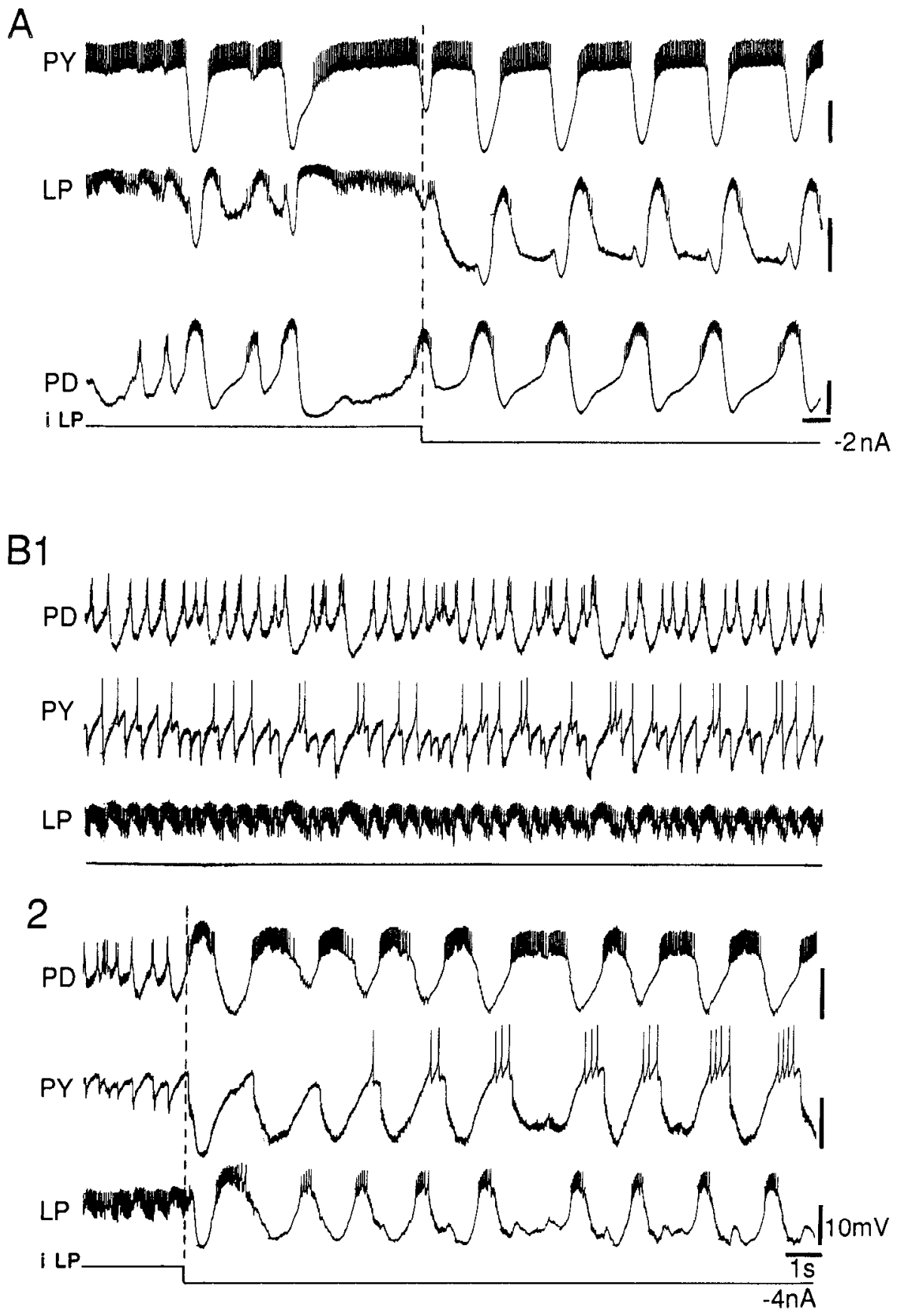

Figure 12. The pyloric patterns induced by muscarinic agonists can be very sensitive to membrane potential of individual neurons. Experimental conditions are as for Figure 11. $A$, The spontaneous rhythmic activity of the pyloric network is irregular (left $)$. When hyperpolarizing current $(-2 n A)$ is injected into the LP neuron, a typical triphasic and regular pyloric pattern appears immediately (right). $B$, The spontaneous activity of the pyloric network is almost tonic (1). Injection of hyperpolarizing current $(-4 \mathrm{nA})$ into the LP neuron (2, right of dashed line) generates a regular triphasic pyloric pattern. $A$ and $B$ are from different preparations.

It has been shown previously that muscarinic modulation could induce the bursting activity of a subset of pyloric neurons, the pacemaker neurons $\mathrm{AB}$ and $\mathrm{PD}$, in an intact network (Marder and Paupardin-Tritsch, 1978; Raper, 1979; Nagy et al., 1985; Marder and Meyrand, 1989) and also when isolated from network (Marder and Eisen, 1984). From the present article, two main results emerged of isolation experiments extended to all pyloric neurons. First, every pyloric neuron appeared to react to direct stimulation of its muscarinic receptors by switching its activity from a tonic mode of firing into a bursting mode. Second, the bursting behavior induced by the muscarinic agonists was different from one neuron to the next.

Activation of individual rhythmogenic properties in all neurons of the pyloric network is a major feature of muscarinic modulation, which sharply contrasts with the effects of other modulators previously tested in similar experimental conditions. Dopamine, 5-HT, and octopamine can each generate a unique variant of the pyloric rhythm (Flamm and Harris-Warrick, 1986a). These patterns are based on individual inhibitions and/or excitations of different subsets of pyloric neurons, but all three amines promote endogenous rhythmogenic properties only in the AB interneuron (Flamm and Harris-Warrick, 1986b). Similarly, proctolin, although modulating the entire pyloric output, directly affects three types of pyloric neurons: it evokes voltage-dependent increase in firing frequency of the isolated LP and PY neurons, and promotes endogenous oscillatory activity in the single AB interneuron (Hooper and Marder, 1987).

The second important result presented here is that the bursting behavior induced by muscarinic stimulation is different from one neuron to the next. Comparison of the oscillations induced 
by the same concentration of muscarinic modulator indicates that the pacemaker neurons $\mathrm{AB}$ and $\mathrm{PD}$ behave like fast and regular oscillators (although $\mathrm{PD}$ is clearly a slower oscillator than $\mathrm{AB}$, as reported earlier by Marder and Eisen, 1984) while the constrictor neurons LP, PY, and IC behave as much slower and irregular oscillators producing repetitive plateau potentials. Moreover, when isolated and deprived of a tonic nonspiking inhibition from the pacemaker neurons (Graubard et al., 1980), the constrictor neurons have to be slightly hyperpolarized in order to oscillate. According to a recent neuronal model (LeMasson et al., 1992), a neuron could modify the balance of its membranes conductances in response to a prolonged perturbation, to keep producing a specific type of activity. It is tempting to consider that the membrane conductances of the constrictor neurons are properly balanced to face the pacemaker-derived tonic inhibition and stay in the appropriate range of membrane potential for oscillations.

Interestingly, similar differences in oscillatory behavior were described for pyloric neurons isolated from network but under the influence of multiple modulatory inputs (i.e., when the connection between anterior ganglia and the STG is left intact; see Bal el al., 1988). Based on their neurotransmitters, at least 13 different pathways were shown to innervate the STG (Marder, 1987; Marder and Nusbaum, 1989) with a marked importance for the peptide containing neurons that constitute a third of the input to the STG (Coleman et al., 1992). But the differences in oscillatory behavior of the pyloric neurons cannot be explained solely by the differential distribution and actions of these multiple modulatory inputs, as indicated by our results obtained under conditions where only one modulator is acting on the neurons. These intrinsic differences in oscillatory behavior might be due to different sets of membrane currents and/or differential sensitivity to the same modulator. So far, except for the LP neuron (Golowasch and Marder, 1992), we lack a general description of the ionic currents expressed by the different types of pyloric neurons. However, recent comparative studies indicate that the pyloric neurons differ from each other at least in the expression of their potassium currents (Hartlinc ct al., 1990; Tierney and Harris-Warrick, 1992).

Among the pyloric neurons, the dilator VD neuron is an exception in that it is a rapid oscillator with short burst duration in the combined preparation, that becomes a slow and regular oscillator with long burst duration when isolated in the presence of a muscarinic agonist. We must point out that whether the VD neuron behaves as a rapid or as a slow oscillator, each oscillation is characterized by the same initial event, a transient high-frequency burst of action potentials (see Fig. 8). When the VD neuron is influenced by multiple modulatory inputs, a strong repolarization terminates the burst within hundreds of milliseconds. When the VD neuron is modulated by oxotremorine, the initial high-frequency burst is followed instead by a sustained depolarization of several seconds. This suggests that muscarinic stimulation interferes somehow with the conductances involved in tcrmination of the plateaus. A likely mechanism is the blockade of a sustained hyperpolarizing current partly carried by $\mathrm{K}^{+}$ ions (Nagy et al., 1985). Induction of plateau properties by blockade of repolarizing conductances has been described in both invertebrate and vertebrate preparations (Hounsgaard and Mintz, 1988; Bal and McCormick, 1992). In the stomatogastric system, the gastropyloric receptor cells (GPR cells) induce plateau properties in their target cells by releasing 5 -HT (Katz et al., 1989). One of several effects exerted by 5 -HT is to decrease a calcium-dependent potassium current (Kiehn and HarrisWarrick, 1992a,b). The ionic basis of the prolonged plateau depolarization evoked by muscarinic modulation in the VD neuron is still unknown. A slowly inactivating $\mathrm{Ca}^{2+}$ current is most probably involved (Nagy et al., 1985).

\section{Pacemaker of the network}

The pacemaker ability of a neuron depends on both its oscillatory properties and its wide synaptic projections onto the rest of the network. The AB neuron projects on all other pyloric neurons, and because it is the fastest pyloric oscillator when isolated from network (Hooper and Marder, 1987; Miller, 1987; Bal et al., 1988), it is considered as the main pacemaker of the network in the combined preparation (with anterior ganglia attached to the STG). The PD neurons are slower oscillators (Marder and Eisen, 1984), and are driven near the $\mathrm{AB}$ frequency through electrical coupling (Hooper and Marder, 1987; Miller, 1987; Bal et al., 1988). But Hooper and Marder (1987) showed that interaction between the two neurons is in both directions, and that the properties of the PD neuron were critical in controlling $\mathrm{AB}$ oscillation period and hence in controlling period of the pyloric network. Under proctolin modulation, for instance, $\mathrm{AB}$ oscillation period is twice as short $(0.5 \mathrm{sec})$ as in the intact network. Later theoretical analysis (Kepler et al., 1990; Abbott et al., 1991) showed that the effect of the PD neuron was more than a simple drag exerted via the electrical coupling on $A B$ activity. It was shown that the effects exerted on an oscillator (like $\mathrm{AB}$ under proctolin) by coupling to a passive neuron (like PD under proctolin), depend on individual properties of both the oscillator and the coupled neuron, and on the strength of the coupling (Kepler et al., 1990). Depending on these parameters, period and burst duration of the oscillator could be increased as well as decreased by electrical coupling to another neuron (Abbott et al., 1991). Taken altogether, these experimental and theoretical studies clearly demonstrated that the pacemaker function is distributed among the $A B$ interneuron and the PD neurons, and indicated that in a changing modulatory environment, modifications of pacemaker rhythm can derive from shifting the relative importance of the oscillatory activity among the two neurons.

We showed in the present article that under moderate muscarinic modulation, the pyloric pacemaker function is shared with a third neuron, the VD neuron, leading to profound modifications of the pyloric pattern. In the conditions of Figure 10, for example, the AB-PD-VD group forms a "composite pacemaker" evoking an original hybrid oscillatory activity that none of the component neurons were able to create alone. This could be regarded as being an experimental validation of theoretical proposition relative to the interplay of electrical coupling and neuronal rhythmogenic properties. Mathematical models indicate that the effects on the output period of varying the coupling coefficient between oscillatory neurons, strongly depend on their endogenous properties (Kepler et al., 1990). We have shown that under muscarinic modulation, the VD neuron is a much slower oscillator than the AB-PD neurons, and that the hybrid activity generated by the three coupled neurons is clearly due to the interaction of the different oscillatory activities of the individual neurons through their electrical coupling. Interestingly, the coupling between the AB-PD neurons and the VD neuron is characterized by a complex rectification. Positive current flows preferably from the VD to the $\mathrm{AB}$ and the PD neurons, whereas negative current flows preferably in the opposite di- 
rection (Peck et al., 1992). This could explain that during the muscarinic-induced hybrid activity strong depolarizing plateau potential in VD increases the oscillation frequency in the ABPD group, while termination of a VD plateau always occurs during repolarization of an AB-PD oscillation (see Figs. $10 F$, 11).

The transfer of the pacemaker function from one neuron (the $\mathrm{AB}$ interneuron) to a group of neurons (AB-PD-VD) not only is due to modifications of the endogenous properties of the component neurons, but also is correlated with modifications of the effects of some of their synaptic connections. For instance, the ability of synaptic inhibition of the $\mathrm{AB}$ interneuron to repolarize the VD neuron and to terminate its burst decreases or disappears in the presence of a muscarinic agonist. As a conscquence, the VD neuron fully expresses its own slow rhythm of oscillation under moderate muscarinic modulation, or fires in phase with the $\mathrm{AB}$ and $\mathrm{PD}$ neurons under stronger muscarinic stimulation. Similar modifications in synaptic efficacy and similar resulting phase shifts were reported to occur during firing of the cholinergic modulatory neuron APM (Nagy and Dickinson, 1983).

Modifications by a modulator of synaptic effects may result indirectly from a general modification of input resistance that would affect the passive spread of current throughout the postsynaptic neurons (Rall, 1981). But a direct action at the synapse is also possible as shown with aminergic modulation of the pyloric network. It was recently reported that amines can modify directly the electrotonic coupling between a pair of neurons by favoring the spread of current in a preferential direction (Peck et al., 1992). The amine, therefore, can bias synaptic coupling in one direction in a reciprocal electrotonic junction. A similar mechanism could underlie the strong enhancement of the electrical influence exerted by the VD neuron on the AB and PD neurons after muscarinic activation.

In conclusion, the data presented here confirm and extend the notion that the pacemaker function can be ascribed to different neurons depending on (1) the state of activation of their endogenous oscillatory properties and (2) the strength of their synaptic connections. In other words, the pacemaker function can be subserved by different neurons depending on the context determined by the modulatory control. Similar results were recently reported for the gastric mill network in the disconnected STG (Elson and Selverston, 1992). Under modulation by the muscarinic agonist pilocarpine, rhythmic pattern generation is devoted to a subset of gastric neurons which does not exert this function in the normal combined preparation. The functional switch is due to the induction of burst generating properties in the neurons by the muscarinic stimulation.

\section{Stability of the pattern}

Under saturating concentrations of muscarinic agonist, the pyloric network displays a stable pattern. It involves firing of all the network neurons, the discharges of which are organized in a triphasic scquence similar to the basic pyloric sequence displayed in a combined preparation. Specific features, however, characterize a muscarinic pattern. The rhythm is generally slower, and phase relationships and duration of neuronal discharges somewhat different, as already discussed for the AB-PD and the VD neurons. Despite these common features, however, the absolute values of parameters of the pattern induced by muscarinic stimulation vary from preparation to preparation. This relative variability is also encountered in other types of preparation. In isolated ganglia of the crayfish, muscarinic stimulation triggers a pattern of fictive locomotion, whose organization is reminiscent of backward walking, although period and phasing are much more variable than in the corresponding motor sequence in intact animal (Chrachri and Clarac, 1990). Rhythmic patterns reminiscent of walking activity are also triggered by muscarinic stimulation in the isolated metathoracic ganglion of the locust, but again these fictive activities are much more irregular than walking patterns in intact locust (Ryckebusch and Laurent, 1993).

Under concentrations of muscarinic agonists slightly above threshold, the induced pyloric pattern is much more variable from preparation to preparation, and in a single preparation may be instable and very sensitive to slight variations in membrane potential of a single neuron (see Fig. 12). A possibility is that a number of building blocks involved in the generation of motor patterns, such as neuronal properties (pacemaker potential, bistability, postinhibitory rebound, delayed discharge) and efficacy of chemical and electrical synapses (Getting, 1989), are modified simultaneously by muscarinic stimulation, but at different thresholds. One may speculate that a proper balance for stable pattern is obtained only when all modified building blocks are sufficiently activated, and that this presumably occurs at higher concentrations of the modulator.

None of the patterns induced by a single modulatory stimulation (Flamm and Harris-Warrick, 1986a; Hooper and Marder, 1987; present results) fully mimics pyloric patterns spontaneously produced in vitro in the combined preparation, or in vivo (Rezer and Moulins, 1983). This is another indication that several modulatory inputs must act in concert to promote a given pattern (see Harris-Warrick and Marder, 1991). That parallel control by multiple modulatory afferents increases the safety factor for stable pattern production is illustrated, for instance, by the effects of the cholinergic modulatory neuron APM. The APM neuron induces specific stable pyloric and gastric patterns in the combined preparation with other modulatory inputs present (Nagy and Dickinson, 1983; Dickinson et al., 1988; Nagy et al., 1988), whereas it induces much more labile patterns when other modulatory inputs are suppressed (Bal, 1991).

\section{Muscarinic action on rhythmogenic properties of excitable cells}

Excitable cells that endogenously fire in bursts have long been a matter of interest in the invertebrates as well as in the vertebrates (Llinas, 1988) because they represent a basis for the generation of timed rhythmic activities in central networks. ACh, via activation of muscarinic receptors, is one of the modulators that control rhythmic activity of excitable cells. In the bullfrog sympathetic neurons, repetitive activity is modulated by $I_{\mathrm{M}}$, an outward $\mathrm{K}^{+}$current that activates very slowly (Brown and Adams, 1980). It tends to damp any oscillatory tendency in the range of voltage in which it is activated. Muscarinic agents inhibit $I_{\mathrm{M}}$ and thus enhance repetitive discharge by decreasing the stability of the membrane potential. This current has also been found in a number of other cell types such as hippocampal and cortical cells, where it is also inhibited by $\Lambda \mathrm{Ch}$ (see Brown, 1988, for a review). Activation of muscarinic receptors by ACh is also involved in slowing down the heartbeat frequency by controlling the rate of pacemaking of the heart cells. It has been shown that $\mathrm{ACh}$ affects several currents of the heart cells (see Hartzell, 1988, for a review). Together with other neurotransmitters, ACh is also involved in a sophisticated control of the thalamocortical rhythmic processing in the vertebrate brain, where it results in a pronounced inhibition of rhythmic burst 
firing and the appearance of single spike activity (McCormick, 1992). In crustaceans, a muscarinic excitation of rhythmically active cardiac motor neurons is due to a sustained voltagedependent inward current, predominantly selective for sodium ions (Freschi and Livengood, 1989).

The mechanisms involved in modulation of pyloric neurons by muscarinic agonists remain to be tested, as well as the possible involvement of different subtypes of crustacean muscarinic receptors (Freschi, 1991). Whatever these mechanisms, however, muscarinic modulation of the firing mode provides extensive control on pyloric network operation that ranges from a simple on and off command to a fine tuning of the rhythmic activity.

\section{References}

Abbott LF, Marder E, Hooper SL (1991) Oscillating networks: control of burst duration by electrically coupled neurons. Neural Comput 3:487-497.

Ayers JA, Carpenter GA, Currie S, Kinch J (1983) Which behavior does the lamprey central motor program mediate? Science 221:13121314.

Bal T (1991) Mécanismes cellulaires impliqués dans la reconfiguration fonctionnelle des réseaux neuronaux stomatogastriques des crustacés: analyse électrophysiologique et pharmacologique par photodissection in situ. PhD thesis, Université de Bordeaux I.

Bal T, McCormick DA (1992) Ionic basis of oscillation and $30-60 \mathrm{~Hz}$ fring in the thalamic reticular nucleus ( $\mathrm{nRt}$ ), a mammalian pacemaker. Soc Neurosci Abstr 18:1392.

Bal T, Nagy F, Moulins M (1988) The pyloric central pattern generator in crustacea; a set of conditional neuronal oscillators. J Comp Physiol [A] 163:715-727.

Bekoff A, Nusbaum MP, Sabichi AL, Clifford M (1987) Neural control of limb coordination. I. Comparison of hatching and walking motor output patterns in normal and deafferented chicks. J Neurosci 7:2320 2330.

Beltz B, Eisen JS, Flamm R, Harris-Warrick RM, Hooper SL, Marder E (1984) Serotonergic innervation and modulation of the stomatogastric ganglion of three decapod crustaceans (Panulirus interruptus, Homarus americanus and Cancer irroratus). J Exp Biol 109:35-54.

Berkinblit MB, Deliagina TG, Feldman AG, Gelfand IM, Orlovsky GN (1978) Generation of scratching. Il. Nonregular regimes of generation. J Neurophysiol 41:1058-1668.

Bidaut M (1980) Pharmacological dissection of pyloric network of the Iobster stomatogastric ganglion using picrotoxin. J Neurophysiol 44: 1089-1101.

Brown DA (1988) M-Currents: an update. Trends Neurosci 11:294299.

Brown DA, Adams PR (1980) Muscarinic suppression of a novel voltage-sensitive $\mathrm{K}^{+}$-current in a vertebrate neurone. Nature 283: 673-676.

Calabrese RL, Angstadt JD, Arbas EA (1989) A neural oscillator based on reciprocal inhibition. In: Perspectives in neural systems and behavior (Carew TJ, Kelley DB, eds), pp 33-50. New York: Liss.

Cazalets JR, Nagy F, Moulins M (1990a) Suppressive control of the crustacean pyloric network by a pair of identified interneurons. I. Modulation of the motor pattern. J Neurosci 10:448-457.

Cazalets JR, Nagy F, Moulins M (1990b) Suppressive control of the crustacean pyloric network by a pair of identified interneurons. II. Modulation of neuronal properties. J Neurosci 10:458-468.

Chrachri A, Clarac F (1990) Fictive locomotion in the fourth thoracic ganglion of the crayfish, Procambarus clarkii. J Neurosci 10:707-719.

Coleman MJ, Nusbaum MP, Cournil I, Claiborne BJ (1992) Distribution of modulatory inputs to the stomatogastric ganglion of the crab, Cancer borealis. J Comp Neurol 325:581-594.

Delcomyn F (1980) Neural basis of rhythmic tehavior in animals. Science 210:492-498.

Dickinson PS, Nagy F, Moulins M (1988) Control of central pattern generators by an identified neurone in crustacea: activation of the gastric mill motor pattern by a neurone known to modulate the pyloric network. J Exp Biol 136:53-87.

Elson RC, Selverston AI (1992) Mechanisms of gastric rhythm generation in the isolated stomatogastric ganglion of spiny lobsters: burst- ing pacemaker potentials, synaptic interactions, and muscarinic modulation. J Neurophysiol 68:890-907.

Flamm RE, Harris-Warrick RM (1986a) Aminergic modulation in lobster stomatogastric ganglion. I. Effects on motor pattern and activity of neurons within the pyloric circuit. J Neurophysiol 55:847865.

Flamm RE, Harris-Warrick RM (1986b) Aminergic modulation in lobster stomatogastric ganglion. II. Target neurons of dopamine, octopamine, and serotonin within the pyloric circuit. J Neurophysiol 55:866-881.

Freschi JE (1991) The effect of subtype-selective muscarinic receptor antagonists on the cholinergic current in motoneurons of the lobster cardiac ganglion. Brain Res 552:87-92.

Freschi JE, Livengood DR (1989) Membrane current underlying muscarinic cholinergic excitation of motoneurons in lobster cardiac ganglion. J Neurophysiol 62:984-995.

Gelfand IM, Orlovsky GN, Shik ML (1988) Locomotion and scratching in tetrapods. In: Neural control of rhythmic movements in vertebrates (Cohen AH, Rossignol S, Grillner S, eds), pp 167-199. New York: Wiley.

Getting PA (1989) Emerging principles governing the operation of neural networks. Annu Rev Neurosci 12:185-204.

Golowasch J, Marder E (1992) Ionic currents of the lateral pyloric neuron of the stomatogastric ganglion of the crab. J Neurophysiol 67: 318-331.

Graubard K, Raper JA, Hartline DK (1980) Graded synaptic transmission between spiking neurons. Proc Natl Acad Sci USA 77:37333735.

Harris-Warrick RM (1988) Chemical modulation of central pattern generators. In: Neural control of rhythmic movements in vertebrates (Cohen AH, Rossignol S, Grillner S, eds), pp 285-331. New York: Wiley.

Harris-Warrick RM, Johnson BR (1989) Motor pattern networks: Flexible foundations for rhythmic pattern production. In: Perspectives in neural systems and behavior (Carew T, Kelley D, eds), pp 51-71. New York: Liss.

Harris-Warrick RM, Marder E (1991) Modulation of neural networks for behavior. Annu Rev Neurosci 14:39-57.

Harris-Warrick RM, Marder E, Selverston AI, Moulins M, eds (1992a) Dynamic biological networks: the stomatogastric nervous system. Boston: MIT Press.

Harris-Warrick RM, Nagy F, Nusbaum MP (1992b) Neuromodulation of stomatogastric networks by identified neurons and transmitters. In: Dynamic biological networks: the stomatogastric nervous system (Harris-Warrick RM, Marder E, Selverston AI, Moulins M, eds), pp 87-137. Boston: MIT Press.

Hartline DK, Gassie DV, Tomiyasu BA, Jones BR (1990) Ionic current fingerprints in lobster stomatogastric neurons. Soc Neurosci Abstr 16: 1131 .

Hartzell HC (1988) Regulation of cardiac ion channels by catecholamines, acetylcholine and second messenger systems. Prog Biophys Mol Biol 52:165-247.

Hooper SL, Marder E (1987) Modulation of the lobster pyloric rhythm by the peptide proctolin. J Neurosci 7:2097-2112.

Hounsgaard J, Mintz I (1988) Calcium conductance and firing properties of spinal motoneurones in the turtle. J Physiol (Lond) 398:591603.

Katz PS, Harris-Warrick RM (1990) Actions of identified neuromodulatory neurons in a simple motor system. Trends Neurosci 13:367373.

Katz PS, Eigg MH, Harris-Warrick RM (1989) Serotonergic/cholinergic muscle receptor cells in the crab stomatogastric nervous system. I. Identification and characterization of the gastropyloric receptor cells. J Neurophysiol 62:558-570.

Kepler TB, Marder E, Abbott LF (1990) The effect of electrical coupling on the frequency of model neuronal oscillators. Science 248: 83-85.

Kiehn O, Harris-Warrick RM (1992a) Serotonergic stretch receptors induce plateau properties in a cruslacean molor neuron by a dualconductance mechanism. J Neurophysiol 68:485-495.

Kiehn O, Harris-Warrick RM (1992b) 5-HT modulation of hyperpolarization-activated inward current and calcium-dependant outward current in a crustacean motor neuron. J Neurophysiol 68:496508 .

LeMasson G, Marder E, Abbott LF (1992) Activity-dependent regulation of conductances in model neurons. Science 259:1915-1917. 
Llinas R (1988) The intrinsic electrophysiological properties of mammalian neurons: insights into central nervous system function. Science 242:1654-1664.

Marder E (1976) Cholinergic motor neurones in the stomatogastric system of the lobster. J Physiol (Lond) 257:63-86.

Marder E (1987) Neurotransmitters and neuromodulators. In: The crustacean stomatogastric system. A model for the study of central nervous systems (Selverston AI, Moulins M, eds), pp 263-300. Berlin: Springer.

Marder E, Eisen JS (1984) Electrically coupled pacemaker neurons respond differently to same physiological inputs and neurotransmitters. J Neurophysiol 51:1362-1374.

Marder E, Meyrand P (1989) Chemical modulation of an oscillatory neural circuit. In: Neuronal and cellular oscillators (Jacklet JW, ed), pp 317-338. New York: Dekker.

Marder E, Nusbaum MP (1989) Peptidergic modulation of the motor pattern generators in the stomatogastric ganglion. In: Perspectives in neural systems and behavior (Carew TC, Kelley D, eds), pp 73-91. New York: Liss.

Marder E, Paupardin-Tritsch D (1978) The pharmacological properties of some crustacean neuronal acetylcholine, $\gamma$-aminobutyric acid, and L-glutamate responses. J Physiol (Lond) 280:213-236.

McCormick DA (1992) Neurotransmitter actions in the thalamus and cerebral cortex and their role in neuromodulation of thalamocortical activity. Prog Neurobiol 39:337-388.

McCrohan CR (1988) Modification of central pattern generation in invertebrates. Comp Biochem Physiol [A] 90:17-22.

Miller JP (1987) Pyloric mechanisms. In: The crustacean stomatogastric system. A model for the study of central nervous systems (Selverston, AI, Moulins M, eds), pp 109-136. Berlin: Springer.

Miller JP, Selverston AI (1979) Rapid killing of single neurons by irradiation of intracellularly injected dye. Science 206:702-704.

Miller JP, Selverston AI (1982) Mechanisms underlying pattern generation in lobster stomatogastric ganglion as determined by selective inactivation of identified neurons. II. Oscillatory properties of pyloric neurons. J Neurophysiol 48:1378-1391.

Moulins M, Cournil I (1982) All-or-none control of the bursting properties of the paccmaker ncurons of the lobster pyloric pattern generator. J Neurobiol 13:447-458.

Moulins M, Nagy F (1985) Extrinsic inputs and flexibility in the motor output of the lobster pyloric neural network. In: Model neural networks and behavior (Selverston AI, ed), pp 49-68. New York: Plenum.

Mulloney BM (1987) Neural circuits. In: The crustacean stomatogastric system. A model for the study of central nervous systems (Selverston AI, Moulins M, eds), pp 57-75. Berlin: Springer.

Nagy F, Dickinson PS (1983) Control of a central pattern generator by an identified modulatory interneurone in crustacea. I. Modulation of the pyloric motor output. J Exp Biol 105:33-58.

Nagy F, Miller JP (1987) Pyloric pattern generation in Panulirus interruptus is terminated by blockade of activity through the stoma- togastric nerve. In: The crustacean stomatogastric system. A model for the study of central nervous systems (Selverston AI, Moulins M, eds), pp 136-139. Berlin: Springer.

Nagy F, Benson JA, Moulins M (1985) Cholinergic inputs reduce a steady outward $\mathrm{K}^{+}$current allowing activation of a $\mathrm{Ca}^{2+}$ conductance which underlies the burst-generating oscillations in lobster pyloric neurons. Soc Neurosci Abstr 11:1022.

Nagy F, Dickinson PS, Moulins M (1988) Control by an identified modulatory neuron of the sequential expression of plateau properties of, and synaptic inputs to, a neuron in a central pattern generator. $J$ Neurosci 8:2875-2886.

Nagy F, Bal T, Cardi P (1992) Dynamic rewiring of CPG circuits in a simple nervous system. In: Analysis and modeling of neural systems (Heckman FH, ed), pp 339-351. Boston: Kluwer.

Pearson KG (1987) Central pattern generation: a concept under scrutiny. In: Advances in physiological research (McLennan H, Ledsome JR, McIntosh CHS, Jones DR, eds), pp 167-185. New York: Plenum.

Peck JH, Johnson BR, Harris-Warrick RM (1992) Amine modulation of electrical coupling in the pyloric network of the lobster stomatogastric ganglion. Soc Neurosci Abstr 18:1055.

Rall W (1981) Functional aspects of neuronal geometry. In: Neurones without impulses (Roberts A, Bush BMH, eds), pp 223-254. Cambridge: Cambridge UP.

Raper JA (1979) Nonimpulse mediated synaptic transmission in the stomatogastric ganglion of the spiny lobster. $\mathrm{PhD}$ thesis, University of California at San Diego.

Rezer E, Moulins M (1983) Expression of the crustacean pyloric pattern generator in the intact animal. J Comp Physiol [A] 153:17-28.

Rezer E, Moulins M (1992) Humoral induction of pyloric rhythmic output in lobster stomatogastric ganglion: in vivo and in vitro studies. J Exp Biol 163:209-230.

Russell DF (1979) CNS control of pattern generators in the lobster stomatogastric ganglion. Brain Res 177:598-602.

Ryckebusch S, Laurent G (1993) Rhythmic patterns evoked in locust leg motor neurons by the muscarinic agonist pilocarpine. J Neurophysiol 69:1583-1595.

Selverston AI, Moulins M (1985) Oscillatory neural networks. Annu Rev Physiol 47:29-48.

Selverston AI, Moulins M (1987) The crustacean stomatogastric system. A model for the study of central nervous systems. Berlin: Springer.

Selverston AI, Russell DF, Miller JP, King DG (1976) The stomatogastric nervous system: structure and function of a small neural network. Prog Neurobiol 7:215-290.

Selverston AI, Miller JP, Wadepuhl M (1983) Cooperative mechanisms for the production of rhythmic movements. SEB Symp 37:5587.

Tierney AJ, Harris-Warrick RM (1992) Physiological role of the transient potassium current in the pyloric circuit of the lobster stomatogastric ganglion. J Neurophysiol 67:599-609. 